\title{
ANÁLISE DE GRUPOS DE EXPERIMENTOS EM BLOCOS COMPLETOS AUMENTADOS, ATRAVÉS DO PACOTE COMPUTACIONAL SAS.
}

\author{
ELISETE ALLEONI MARCOS \\ Economista Doméstica
}

Orientadora: Prof. Dr. Maria Cristina Stolf Nogueira

Dissertação apresentada à Escola Superior de Agricultura "Luiz de Queiroz", da Universidade de São Paulo, para obtença do título de Mestre em Agronomia, Ārea de Concentraça: Estatística e Expe rimentação Agronòmica.

P I R A C I C A B A

Estado de São Paulo - Brasil

$$
\text { Julho - } 1994
$$


Ficha catalografica preparada pela Secão de Livrog da Divisáo de Biblioteca e Documentaç̃o - PCLQ/USP

Marcos, Elisete Alleoni

M32la Análise de grupos de experimentos em blocos comple tos aumentados, atravis do pacote computacional SAS.

Piracicaba, 1994.

91p. ilus.

Diss. (Mestre) - ESALQ

Bibliografia.

1. Delineament de experimento 2. Estatistica expe rimental 3. Programa de computador 4. SAS I. Escola Superior de Agricultura Luiz de Queiroz, Piracicaba

CDD $\quad 519.5$ 
ii.

\section{ANÁLISE DE GRUPOS DE EXPERIMENTOS EM BLOCOS COMPLETOS AUMENTADOS, ATRAVÉS DO PACOTE COMPUTACIONAL SAS.}

\section{ELISETE ALLEONI MaRcos}

Aprovada em: 02.09 .94

Comisøão julgadora:

Prof-. Dra. Maria Cristina Stolf Nogueira ESALQ/USP

Prof. Dr. Antonio Francisco Iemma ESALQ/USP

Prof. Dr. Sérgio do Nascimento Kronka FCAVJ/UNESP

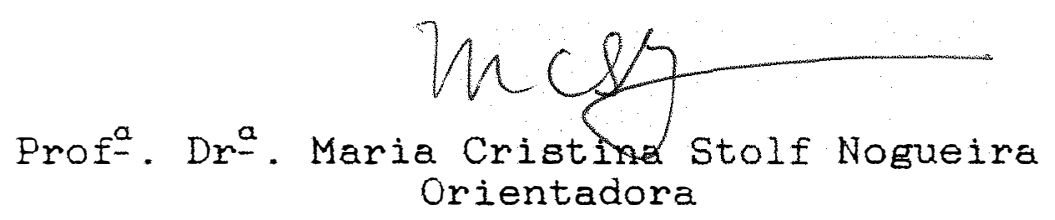


iii.

Dedicada aos meus tres queridos:

Julinho, Ma e Du, com muito carinho. 


\section{AGRADECI MENTOS}

A todas as pessoas que no momento certo foram tão amigas e conseguiram, com um simples gesto, me mostrar que eu nunca estive sozinha.

Aos meus pais que sempre souberam me entender tå bem.

Ao Julinho, por estar sempre tão presente.

Aos meus filhos, $M a$ e Du, que com sua sinceridade e lógica inabalável me fizeram crescer em todos os sentidos.

A Maria Cristina Stolf Nogueira, pela paciencia, amizade e prontidão em todos os momentos de dúvida.

Ao Antonio Francisco Iemma, pelo incentivo desde 0 começo da minha vida profiseional.

A Roseli A. Leandro, por ser eempre tão amiga.

A Rosemeire, que fez tanta falta, por ter sido uma pessoa sensata e serena.

Ao Jose Eduardo Corrente, pelo interesse e por estar sempre pronto a dar apoio. 
A Ana Maria, Expedita, Luciane, Solange, Rosa e Rosni por mostrarem sempre tanta disposifão em ajudar.

A Cristina Bombo, sempre pronta a me subetituir em todos os momentos necessários.

A CAPES, pela bolea de estudos concedida.

Aos amigos do Curso de pos-Graduação, pela amizade e companheirismo. 
vi.

\section{SUMARIO}

Página

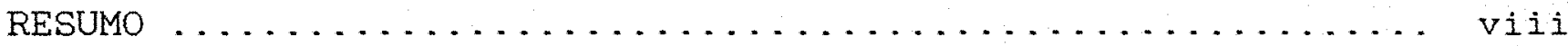

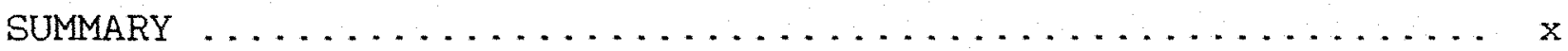

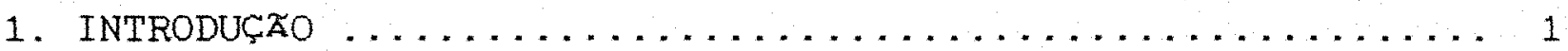

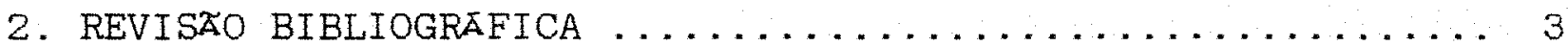

3. DESENVOLVIMENTO TEORICO ........................

3.1. Caracterizaça ........................ 13

3.2. Modelo Matematico ........................ 14

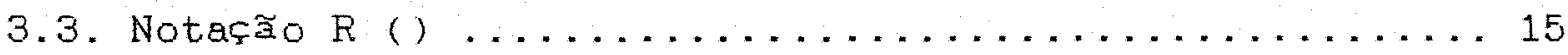

3.4. Estimabilidade ...................... 16

3.4.1. Forme Geral de uma Função Eetimável ......... 18

3.4.2. Funç̧es Estináveis Tipo $I \ldots \ldots \ldots \ldots 27$

3.4.3. Funçธes Estimáveis Tipo II . . . . . . . . . 37

3.4.4. Funçoes Estimáveis Tipo III . . . . . . . . . 39

3.4.5. Funçธ̌es Estimáveis Tipo IV ............ 43

3.5. Esperanca do Quadrado Medio ................ 43

4. MATERIAL E METODOS ....................... 53

4.1. Análise Individual .................... 56

4.2 . Análise Conjunta .................... 57

5. RESULTADOS E DISCUSSÃO .................... 59

5.1. Análise Individual ..................... 59

5.2. Análise Conjunta ...................... 73 
vii.

6. CONCLUSOES .............................. 84

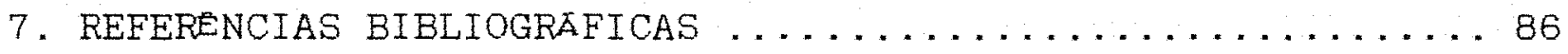

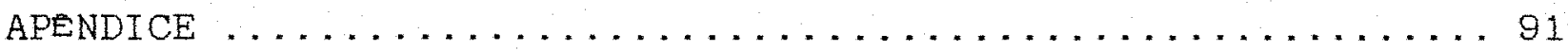


viii.

\title{
ANÁLISE DE GRUPOS DE EXPERIMENTOS EM BLOCOS COMPLETOS AUMENTADOS. ATRAVÉS DO PACOTE COMPUTACIONAL SAS
}

\author{
Autora: ELISETE ALLEONI MARCOS \\ Orientadora: PROF. DR. MARIA CRISTINA STOLF NOGUEIRA
}

\section{RESUMO}

O delineamento em blocos completos aumentados (blocos de Federer) geralmente e utilizado quando o experimento apresenta um numero relativamente grande de tratamentos a serem avaliados. Para este caso, consideram-se dois grupos de tratamentos:

- Tratamentos comune, que eão repetidos j vezes e estão presentes em todos os blocos;

- Tratamentos regulares, que aparecem uma única vez em um dos blocos.

Da forma como esse delineamento é estruturado, o uso da enálise de variancia convencional gera problemas no momento de serem testadas as hipóteses de interesse, em geral efetuadas peIa estati etica "F". As dificuldades para a análise tornam-se ainda maiores quando se consideram grupos de experimentos em blocos aumen tados. 
ix.

Assim, o presente trabalho, conduzido no Departamento de Matemática e Estatística da Escola Superior de Agricultura "Luiz de Queiroz"/USP, teve como objetivo desenvolver um procedimen to para as análises individuais e a conjunta, segundo o delineamento proposto para grupos de experimentos, através da aplicação da metodologia utilizada pelo pacote computacional SAS (Statistical Analysis System).

Com o auxílio de um conjunto de dados hipotéticos, adotou-se o modelo matemático para o delineamento em blocos completos aumentados, onde foram consideradas as funçoes estimáveis e as hipoteses a serem testadas pelas quatro somas de quadrados fornecidas pelo SAS. Calcularam-se, tambem, as esperancas dos quadrados medios, a fim de compor o denominador para a estatística " $F$ ".

Como aplicaça desta técnica realizaram-se análises individuaio e a conjunta de dados de produção de cana-de-açúcar ( $t / h a)$, provenientes de cinco experimentos conduzidos em diferentes locais.

\section{Concluiu-se que:}

- A Soma de Quadradoe Tipo I mostrou não ser a mais indicada para o delineamento em estudo, tanto na analise individual como na conjunta.

- A Soma de Quadrados Tipo III parece ser a mais adequada, desde que a estatistica "F" seja obtida através da opcão TEST do comando RANDOM na PROC GLM do SAS. 
$\mathrm{x}$.

\title{
ANALYSIS OF EXPERIMENTAL GROUPS IN AUGMENTED COMPLETE BLOCKS. THROUGH OUT SOFTWARE SAS.
}

\author{
Author: ELISETE ALLEONI MARCOS \\ Adviser: PROF. DR.MARIA CRISTINA STOLF NOGUEIRA
}

\section{SUMMARY}

The design in augmented complete blocks (Federer blocks) generally is used when the experiment presents a relatively large number of treatments to be evaluated. In this case two groups of experiments are considered:

- Common treatments, that are repeated $j$ times and are presented in all blocks;

- Regular treatments, that appear only once in one of the blocks.

In the way as this design is structured, the conventional analysis of variance produces problems at the moment of testing the hypothesis of interest, in general made of " $F$ " statistic. The analysis procedure becomes more complicate when groups of experiments in augmented blocks are considered.

Thus, the main objective of this research conducted at Mathematics and Statistics Department of the Escola Superior de 
xi.

Agricultura "Luiz de Queiroz"/USP, State of Să Paulo - Brazil was to develop a procedure for individual and joint analysis, according to the proposed design for groups of experiments, through out the applied methodology used by the software SAS (Statistical Analysis System).

Using a ficticious data set, it was adopted a mathematical model for the augmented complete blocks design, where were considered the estimable functions and the hypothesis to be tested through the four sum of squares provided by SAS. It was also found the expectation of the mean square, in order to compose the denominator for the $F$ statistical test.

As an application of this technic, it was used a data set from sugar cane production ( $t /$ ha) obtained from five experiments carried out in different locations; the individual and joint analysis were done.

It was concluded from this study that the sum of squares Type I didn't show to be the most appropriate for this design. On the other hand, the sum of square Type III showed better results, since the $F$ statistics has been obtained through the option TEST from the statement RANDOM at SAS - Proc GLM. 


\section{INTRODUÇล̃O}

Ná experimentação agronómica, em especial nos programas de melhoramento de plantas, é comum o pesquisador planejar um experimento com a inclusão de um número relativamente grande de tratamentos a serem avaliados.

A dificuldade de se conseguirem áreas que sejam he mogeneas ou então a heterogeneldade ou escassez do material experi mental fez com que FEDERER (1956) desenvolvesse uma classe de deli neamentos experimentais conhecida por "delineamentos aumentados", quando trabalhava em um programa de melhoramento de cana-de-açúcar no "Hawain Sugar Planter"s Association".

De acordo com este autor, um delineamento experimental aumentado e caracterizado pela adiça de tratamentos a qualquer delineamento padrão, como, por exemplo, blocos ao acaso, quadrado latino.

Assim, o delineamento em blocos completos aumentados apresenta dois grupos de tratamentos, a saber:

a.) Tratamentos comuns, que eão repetidos j vezes e estão presentes em todos os blocos.

b.) Tratamentos regulares, que aparecem uma ún1ca vez em um dos blocos. 
Neste caso, os tratamentas comuns são aqueles que apresentam comportamento já conhecido e atuarão como uma espécie de controle ou testemunha para os tratamentos regulares ou novos que se tem interesse em testar.

Embore a literature apresente vários trabalhos referentes a este assunto pouco se tem escrito a respeito, no que se refere a execução de análises utilizando os pacotes computacionais desenvolvidos atualmente.

Uma vez que as tecnicas computacionais se tornaram ferramentas uteis para a execuça de análises estatísticas, pode ser interessante o estudo dessas novas técnicas para análise do delineamento em blocos completos aumentados.

O objetivo deste trabalho e, portanto, anelisar es te delineamento atraves da eplicação da metodologia utilizada no pacote computacional SAS ( Statistical Analysis System, 1987), um dos mais importantes pacotes estatísticos de uso mundial. Através de um exemplo hipotetico será explicada a metodologia em que está baseada a análise e, com dados reais, uma análise de um grupo de experimentos, planejado segundo o delineamento em blocos completos aumentados, será apresentada. 


\section{REVISAOO BIBLIOGRAFICA}

FEDERER (1956) trabalhando em uma pesquisa de comparaça do desempenho de plântulas de diferentes clones, desenvolveu uma metodologia que possibilitou a comparaça de variedades no vas chamadas regulares, com varledades ja conhecidas, chamadas comuns. Deu a esse novo delineamento o nome de "delineamento aumenta do". O mesmo autor em 1961, atraves de dois outros trabalhos, de finiu esse delineamento como um delineamento padrão onde são adicionedoe novos tratamentos que podem ou nãa apresentar o mesmo número de repetiçธ్s.

PIMENTEL GOMES \& GUIMARAES (1958) propuseram um mé todo de análise conjunta de experimentos em blocos completos casus lizados com alguns tratamentos comuns, assumindo que os dados a se rem analisados fossem provenientes de $g$ diferentes experimentos em blocos com repetiçoses $e k=z+c$ tratamentos, onde $c$ säo 08 tratamentos comuns e $z$ os regulares. Dessa forma, o número total de tratamentos fol representado por $r=g z+c$.

De acordo com esses autores, o esquema da análise para cada experimento seria feito de forma usual, isto é: 


\begin{tabular}{cc}
\hline CV & GL \\
\hline Blocos & $(r-1)$ \\
Tratamentos & $(z+c-1)$ \\
Residuo & $(r-1)(z+c-1)$ \\
\hline Total & $r(z+c)-1$ \\
\hline
\end{tabular}

E, para analise confunta,

\begin{tabular}{lc}
\hline CV & GL \\
\hline Experimentos & $(g-1)$ \\
Blocos d. de Exper. & $g(r-1)$ \\
Tratamentos (ajust.) & $(g z+c-1)$ \\
Trat. comuns x Exper. & $(c-1)(g-1)$ \\
Resíduo & $g(r-1)(z+c-1)$ \\
\hline Total & $g r(z+c)-1$ \\
\hline
\end{tabular}

Continuando nessa mesma Iinha de pesquisa, PIMENTEL GOMES (1970) ampliou o uso desse método para os casos onde o numero de repetiços e o numero de tratamentos regulares poderiam variar de um experimento para o outro. Isso pode acontecer quando se incluem $\mathrm{g}$ experimentos em blocos completos casualizados, com 0 i-esimo experimento recebendo $z_{i}$ tratamentos regulares $e$, também, c tratamentos comuns com $r_{i}$ repetiç̋es. Neste caso, o número total de tratamentos foi representado por $v=\sum_{i} z_{i}+c$. A análise de 
variancia, obtida da maneira usual, para o i-éeimo experimento, originara uma soma de quadrado de reaiduo indicada por $S Q R_{i}$.

Assim, a analise conjunta fol obtide por:

\begin{tabular}{|c|c|c|c|}
\hline $\mathrm{CV}$ & GL & $S Q$ & $Q M$ \\
\hline Experimentos & $g-1$ & usual & \\
\hline Blocos d. Exper. & $\Sigma r_{i}-g$ & usual & \\
\hline Trat comuns $x$ Exper. & $(c-1)(g-1)$ & usual & \\
\hline Trat (ajust) & $\Sigma z_{i}+c-1$ & por subtração & \\
\hline Resil duo & por subt. & $\Sigma S Q R$ & $s^{2}$ \\
\hline Total & $\sum r_{i}\left(z_{i}+c\right)-1$ & usual & \\
\hline
\end{tabular}

Como uma aplicaça prática desse metodo, CARVALHO (1991) trabalhou com melhoramento genético de soja, adotando o mo de 10:

$$
y_{i j k}=\mu+\tau_{i}+\beta_{j}+\theta_{k}+\delta_{i} \gamma_{i j}+\varepsilon_{i j k}
$$

com:

$$
\begin{aligned}
& \delta_{i}=0 \text { se } i \text { for tratamento regular } \\
& \delta_{i}=1 \text { se } i \text { for tratamento comum }
\end{aligned}
$$


onde:

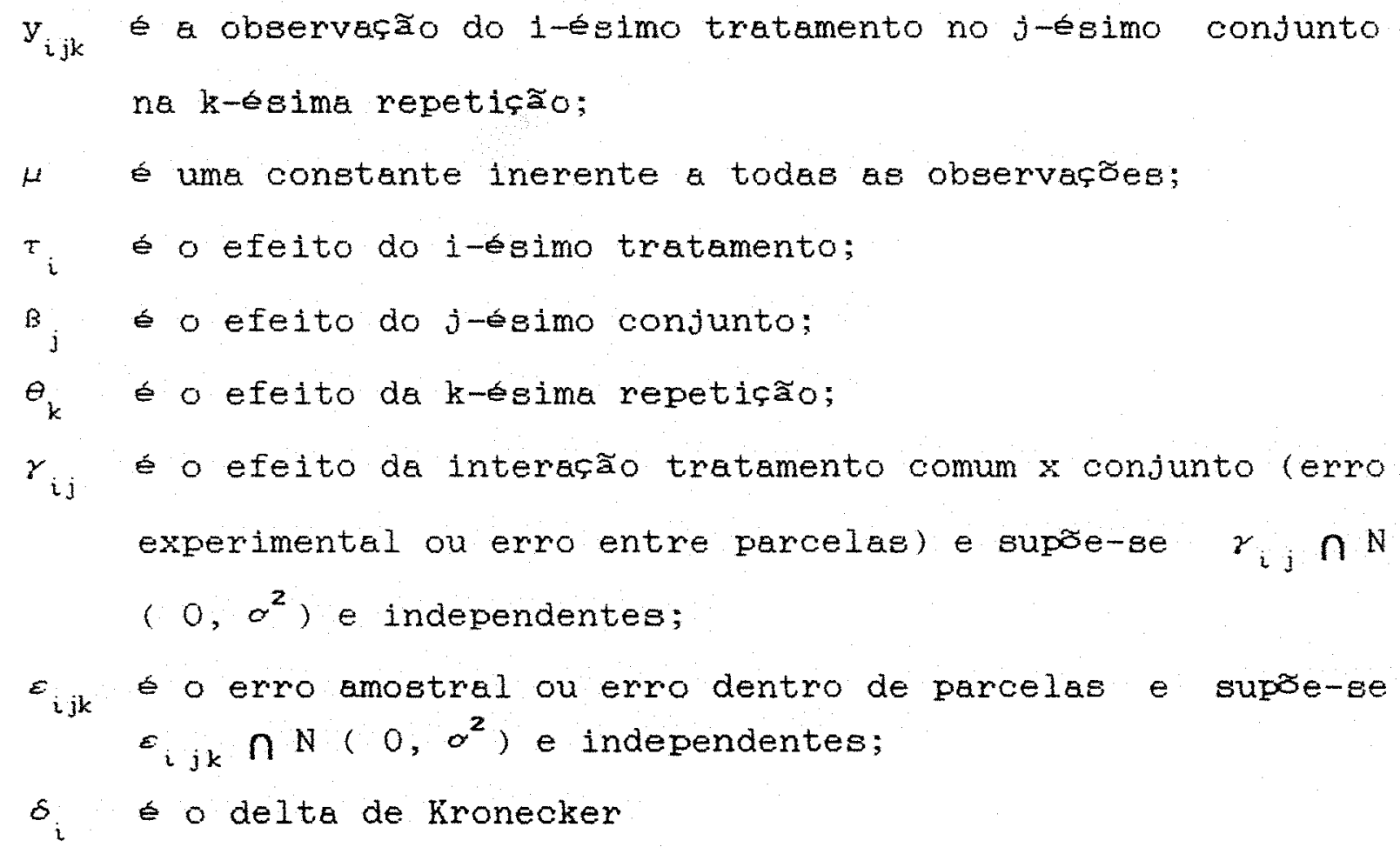

Nesse trabalho considerou: o sistema de equaços normais; uma análise de variancia, envolvendo todos os efeitos do modelo; outra desprezando os tratamentos comuns e outra onde utili zaram-se as medias dos tratamentos comuns, que se repetem dentro de cade conjunto, e as variancies de contrastes entre medias de tratamentos.

NOGUEIRA (1976) estudou a análibe conjunta de expe rimentos em blocos casualizados completos aumentados. Cada experimento apresentou os mesmos $t=c+z$ tratamentos, distribuidos em $r$ blocos onde os c tratamentos, tidos como comuns, apareceram nos $r$ blocos e os z tratamentos, tidos como regulares, foram incluidos uma únlca vez em um dos $r$ blocos. Nesta pesquisa a autora adotou o seguinte modelo: 


$$
y_{i j k}=\mu+t_{i}+I_{k}+b_{j \mid k}+(t I)_{i k}+e_{i j k}
$$

com $i=1, \ldots, t ; j=1, \ldots, r$ e $k=1, \ldots, 1$

onde:

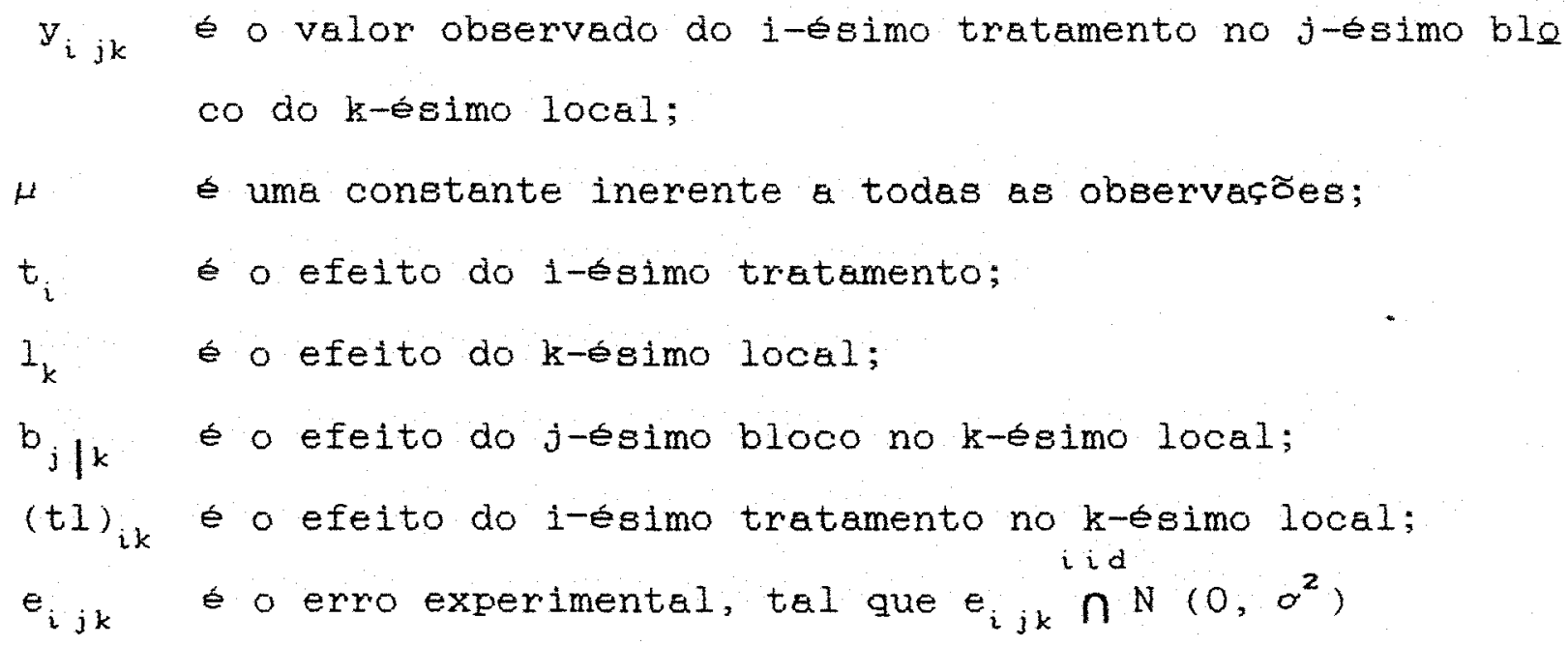

Para a obtenç̃o da Soma de Quadrados de Tratamentos ajustada, fol considerado o modelo de blocos casualizados, isto e:

$$
y_{i j}=\mu+t_{i}+b_{j}+e_{i j}
$$

sendo que: $i=1,2, \ldots, t$

$$
j=1,2, \ldots \ldots, b
$$

onde:

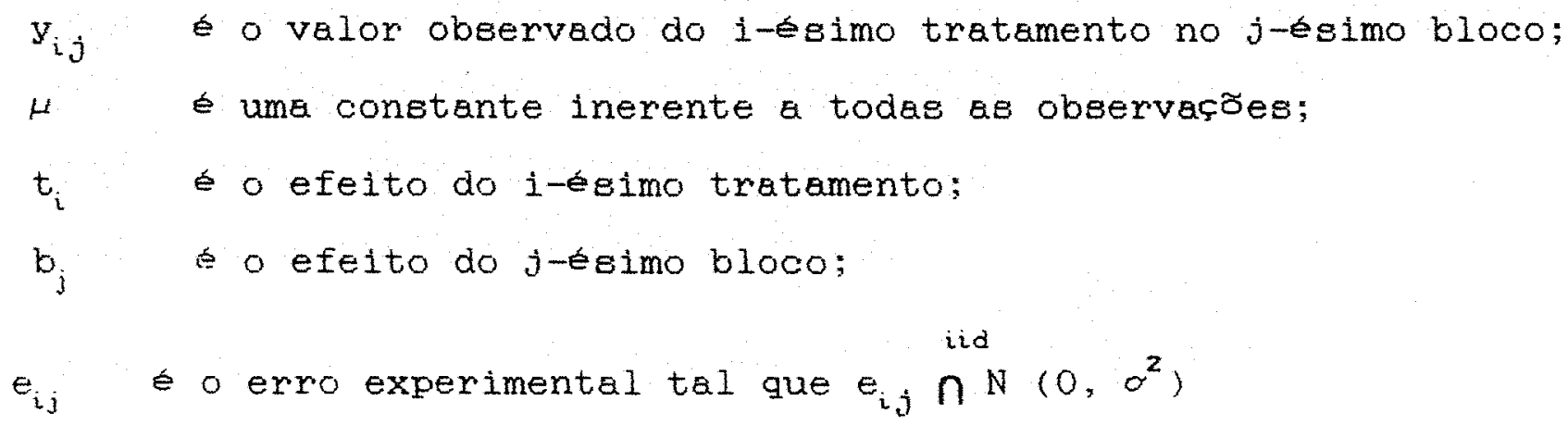


Esse trabalho foi desenvolvido segundo a metodologia desenvolvida por PIMENTEL GOMES \& GUIMARAES (1958) e PIMENTEL GOMES (1970).

Um delineamento aumentado modificado (MAD) foi pre posto por LIN \& POUSWINSKY (1983) para o caso de experimentos que apresentavam um grande número de linhas a serem avaliadas, mas com uma quantidade insuficiente de material para poder repetir o experimento. Impuseram duas restrições, ou sejam, a parcela deveria apresentar o formato quadrado, ou próximo disso e as subparcelas de veriam apresentar 0 desenho $3 \times 3$ ( 3 linhas por 3 colunas).

Essas restriçaes foram estabelecidas para que houvesse uniformidade entre a parcela controle e as 8 subparcelas adjacentes e a homogeneidade da correlação entre parcelas pudesse ser mantida.

Continuando seus estudos, LIN \& POUSWINSKY (1985) desenvolveram um delineamento aumentado modificado, chamado Tipo 2, para o plantio de alguns tipos de cereais e de soje que são plantados em Inhas, onde a diferenca báeica era usar 5 parcelas retangulares arranjadas em linhas paralelas. Utilizaram, como exem plo, um delineamento $5 \times 6$ ( 5 linhas por 6 colunas) e 12 conjuntos de dados hipotéticos. Com isso, investigaram:

i.) A escolha de um metodo ajustado baseado na anaIise de variancia das parcelas controles;

i.) A estimativa da eficiencia relativa do método. Os resultados mostraram que a escolha de um metodo de correcão baseado na análise de variancia é satisfatorio e, em- 
bora as estimativas da eficiencia relativa tenham diferido dos valores populacionais, esses valores podem ser considerados praticamente identicos.

GONÇALVEZ (1984) fez um estudo comparativo entre quatro métodos de estimacão dos componentes de variancia: Henderson-3, Máxima Veroseimilhança, Máxima Verossimilhança Restrita e MIVQUEO (Estimaç̃ Não-Tendenciosa de Mínima Norme), considerando como de efeitos fixos todos os blocos e os tratamentos comuns $e$, como de efeito aleatório, os demais tratamentos.

Estudando o delineamento em bloco aumentados com parcelas eubdivididas no tempo, VIZONI (1984) considerou c variedades comuns, dispostas em b blocos, $z$ variedades regulares que aparecem uma unica vez em todo o experimento e $v$ anos. Todos os blocos apresentavam o mesmo número de parcelas.

Adotou o seguinte modelo matemático:

$$
y_{i j V}=m+t_{i}+b_{j}+(t b)_{i j}+a_{v}+(t a)_{i v}+(b a)_{j V}+e_{i j V}
$$

onde:

$y_{i j v}$ é o valor observado na sub-parcela que recebeu o v-esimo tratamento secundario (anos) dentro do i-esimo tratamento principal no j-éeimo bloco;

m é o efeito da média geral:

$t_{i} \quad$ e ofeito do i-esimo tratamento principal;

$b_{j}$ o efeito do j-ésimo bloco; 
$(t b)_{i j}$ e o efeito da interaçăo do i-ésimo tratamento principal con o j-ésimo bloco, tambern chamado erro (a);

a $\quad$ e efefto do v-ésimo tratamento secundario (anos);

(ta) ${ }_{i v}$ e efeito da interação entre o l-ésimo tratamento principal com o v-ésimo tratamento secundário;

(ba) jv é o efeito da interaçăo entre o j-ésimo blco e o v-ésimo tratamento secundário;

$e_{i j v} \quad$ o erro atribul do a observação $\mathrm{y}_{\mathrm{ijv}}$, chamado erro (b).

Segundo o autor, quando se trabalha com parcelas sub divididas no tempo, não é raro encontrar correlaçoses diferentes en tre duas subparcelas de uma mesma parcela. Nesse trabalho, conside rou-se apenas o caso onde as correlaçoses eram constantes e existia independéncia entre subparcelas e parcelas distintas. Dessa forma, determinou-se o sistema de equaçoes normais, as somas de quadrados doe parámetros, as matrizes de dispereão e os criterios para as comparaçáe múltiplas pelo critério de Tukey. 0 autor concluiu que:

- viável o delineamento aumentado no ezquema de parcelas subdivididas,

- a análise deve ser feita apos o teste de homogenel dade e uniformidade de variancia;

- quando os tratamentos regulares aparecem somente uma vez em todo o experimento, os reel duos podem ser obtidos através de valores singulares da matriz uniforme ou através do modelo adotado. 
Com o objetivo de determinar o sistema de equaçธes normais, as estimativas dos efeitos ajustados de tratamentos, a ma triz de dispersão dos efeitos de tratamentos, as somas de quadrados e a variancia das estimativas dos contrastes possiveis entre duas médies de tratamentos, GREINER (1986) desenvolveu uma análise conjunta de experimentos conduzidos em blocos incompletos balancea dos (BIB) com alguns tratamentos comuns a todos os experimentos.

Trabalhando com análise de covariancia, SILVA(1987) determinou a sistema de equaçoes normais, as estimativas dos efeitos dos parámetroe, as somas de quadrados e suas esperancas matemáticae e, tambem, as distribuicóes das formas quadráticas. Para tanto, adotou o seguinte modelo matemático:

$$
y_{i j}=\mu+\beta_{i}+t_{j}+\gamma x_{i j}+e_{i j} \text {, onde }
$$

$y_{i j}$ o valor observado do bloco i que recebeu o tratamento j;

H. a a média geral;

$\beta_{i}$ e o efeito do blocoi:

$t_{j}$ é o efeito do tratamento j;

$\gamma \Leftarrow 0$ coeficiente de regressão linear de y em relação a $X$;

$x_{i j}=X_{i j}-\bar{X}$, onde $X_{i j}$ gão os valores observados da variável

auxiliar (covariável);

$e_{i j}$ é erro experimental associado à observação $y_{i j}$, onde $e_{i, j} \cap N\left(0, \sigma^{2}\right)$ 
Atraves de um exemplo numérico verificou o seguin

te:

- o modelo permitiu uma estimativa dos efeitos de tratamentos condizente com o objetivo;

- o modelo e o método permitiram obter os efeitos de tratamentos ajustados para blocos e regressão.

Em um estudo com experimentos conduzidos em reticu lados quadrados, eumentado pela adifão de alguns tratamentos comuns a todos os blocos, OLIVEIRA (1990a) aplicou metodos de análise intrablocos e com recuperação da informação interblocos. Em outra pesquisa, o mesmo autor (1990b) usou essa metodologia para o caso de um ensaio em blocos incompletos parcialmente balanceados (PBIB).

Não foram encontrados na literatura trabalhos de pesquisa referentes a delineamentos em blocos aumentados que utilizassem pacotes computacionals. Dessa forma, apesar de muito uteis, os trabalhos sobre o assunto ã̃o escassos. 


\section{DESENVOLVIMENTO TEORICO}

\subsection{Caracterização}

O esquema geral para um experimento em blocos completos aumentados pode ser caracterizado da seguinte forma:

\begin{tabular}{|c|c|c|c|}
\hline $\mathrm{Bloco}$ & $\mathrm{BlOCO}_{2}$ & $\ldots$ & $\mathrm{Bloco}_{\mathrm{J}}$ \\
\hline$A_{1}$ & $A_{1}$ & $\cdots$ & $A_{1}$ \\
\hline $\mathrm{A}_{2}$ & $A_{2}$ & $\cdots$ & $A_{2}^{2}$ \\
\hline$\cdots$ & $\cdots$ & $\cdots$ & $\cdots$ \\
\hline$A_{c}$ & $A_{c}$ & $\cdots$ & ${ }^{A} C_{C}$ \\
\hline$a_{11}$ & $a_{21}$ & $\cdots$ & $a_{J_{1}}$ \\
\hline$a_{12}$ & $a_{22}$ & $\cdots$ & $a_{12}$ \\
\hline$\ldots$ & $\ldots$ & $\cdots$ & $\cdots$ \\
\hline$a_{1 p_{i}}$ & $\mathrm{a}_{2 \mathrm{p}_{2}}$ & & $a_{s p}$ \\
\hline
\end{tabular}

onde:

$A_{1}, A_{2}, \ldots, A_{c}$ representam os tratamentos comuns e os $a_{11}$, $a_{12}, \ldots, a_{1 p_{1}}, \ldots, a_{s_{1}}, a_{s_{2}}, \ldots, a_{s_{j}}$, representam os $z$ tratementos regulares, sendo que $z=\sum_{j} p_{j}$.

Dependendo da necessidade do pesquisador, pode ser interessante a inetalação do experimento em vários locais, eeguin do a mesma estrutura. Neste caso, fica caracterizado um grupo de experimentos em blocos completos aumentados, cujo esquema geral po 
de ser representado por:

\begin{tabular}{|c|c|c|c|c|c|c|c|c|}
\hline $\mathrm{Bloco}_{11}$ & $\mathrm{BlOCO}_{21}$ & $\cdots$ & $\mathrm{Bloco}_{J_{1}}$ & $\cdots$ & $\mathrm{Bloco}_{1 \mathrm{~K}}$ & $\mathrm{BlOCO}_{2 \mathrm{~K}}$ & $\cdots$ & $\mathrm{BlOCO}_{\mathrm{NK}}$ \\
\hline$A_{1}$ & $A_{1}$ & $\cdots$ & $A_{1}$ & & $A_{1}$ & $A_{1}$ & $\cdots$ & $A_{1}$ \\
\hline$A_{2}$ & $A_{2}$ & $\cdots$ & $A_{2}$ & $\ldots$ & $A_{2}$ & $A_{2}$ & $\cdots$ & $A_{2}$ \\
\hline$\cdots$ & $\cdots$ & $\cdots$ & $\cdots$ & $\ldots$ & $\cdots$ & $\cdots$ & $\cdots$ & $\cdots$ \\
\hline$A_{c}$ & $A_{c}$ & $\cdots$ & $A_{c}$ & $\cdots$ & $A_{c}$ & $A_{c}$ & $\cdots$ & $A_{c}$ \\
\hline$a_{11}$ & $a_{21}$ & $\cdots$ & $a_{s_{1}}$ & $\cdots$ & $a_{11}$ & $a_{21}$ & $\cdots$ & $a_{J_{1}}$ \\
\hline$a_{12}$ & $a_{22}$ & $\cdots$ & $a_{n z}$ & $\cdots$ & $a_{12}$ & $a_{22}$ & $\cdots$ & $a_{32}$ \\
\hline$\cdots$ & $\cdots$ & $\cdots$ & $\cdots$ & $\cdots \cdots$ & $\cdots$ & $\cdots$ & $\cdots$ & $\cdots$ \\
\hline$a_{1 p_{1}}$ & $a_{2 p_{2}}$ & & $a_{p_{s}}$ & $\cdots \cdots$ & $a_{1 p_{1}}$ & $a_{2 p_{2}}$ & $\cdots$ & $a_{J P}$ \\
\hline
\end{tabular}

onde os Locais $1,2, \ldots, k$ representam os locais de instalaça do experimento.

\subsection{Modelo Matemático}

Para a análise conjunta de un grupo de experimentos em blocos completos sumentados, sera coneiderado o seguinte me delo:

$$
y_{i j k}=\mu+\lambda_{k}+\alpha_{i}+\beta_{j \mid k}+\gamma_{k i}+\varepsilon_{i j k}
$$

com $i=1,2, \ldots, I \quad j=1,2, \ldots, J \quad$ e $k=1,2, \ldots, K$.

onde: 


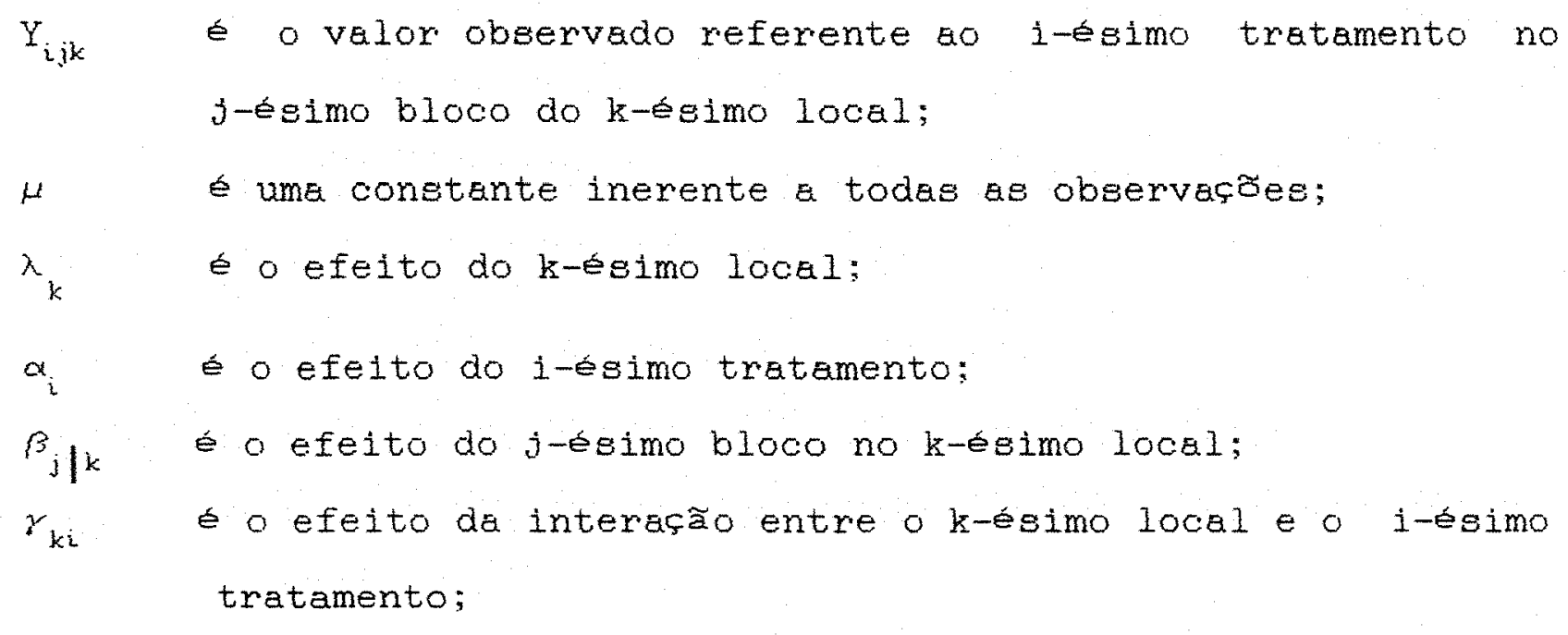

Para o desenvolvimento da análise seré aplicado a notaça $R($ ), desenvolvida por SEARLE (1971) e utilizada em modelos de posto incompleto.

Como essa metodologia é utilizada pelo pacote computacional SAS (Statistical Analysis System, 1987), empregado para a execução da análise em questão, será efetuada a seguir uma abordagem geral dos procedimentos adotados.

\section{3. Notação R C}

De uma maneira geral, a notação $k$ () pode ser descrita da seguinte maneira:

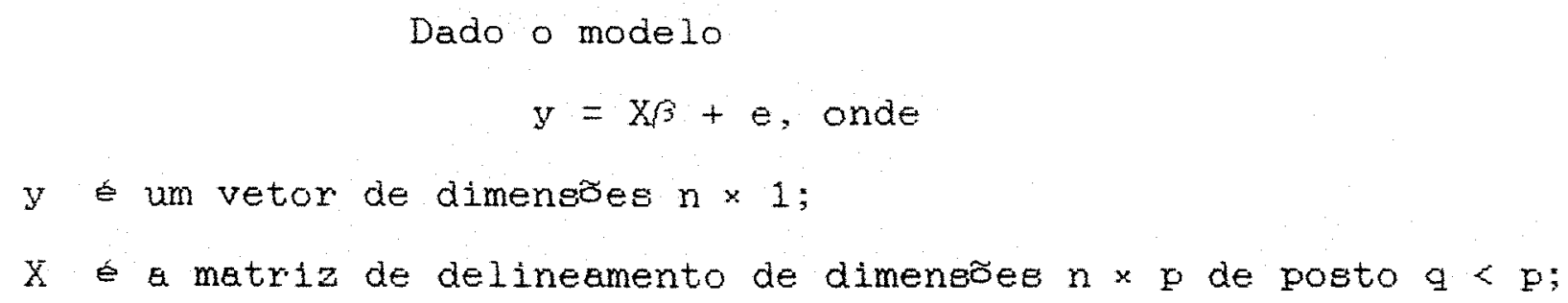


$\beta$ é um vetor de parâmetros de dimensôes $p \times 1$;

e é um vetor não observável de erros aleatorios de dimensões

$n \times 1$ tal que $\mathrm{x} n \mathrm{~N}\left(\phi, \mathrm{r} \boldsymbol{\sigma}^{2}\right)$.

A notação $R$ (), segundo SEARLE (1971) e definida por:

$R(\beta)=\beta^{\circ} X^{\prime} y$, onde $\beta^{\circ}$ elgume soluça de $X X^{\circ} \beta^{\circ}=X^{\prime} y$.

Se $X$ e $\beta$ forem particionados em $\left[X_{1}: X_{2}\right]$ e $\left[\begin{array}{c}\beta_{1} \\ -\beta_{2}\end{array}\right]$,

respectivamente, e se for considerado o modelo:

$$
y=\beta_{2} x_{2}+e, \text { então }
$$

$R\left(\beta_{2}\right)=\beta_{2}^{\circ} X^{\circ}$ y onde $\beta_{2}^{\circ}$ e uma soluça de $X_{2} X_{2} \beta_{2}^{\circ}=X_{2}^{-} y$.

Assim, $\quad R\left(\beta_{1} \mid \beta_{2}\right)=R\left(\beta_{1}, \beta_{2}\right)-R\left(\beta_{2}\right)$.

Ainda segundo SEARLE (1971), $R()$ é uma redução na soma de quadrados e os termos que estarão contidos entre parénteses serão os indicativos do modelo ajustado. Esse metodo pode ser estendido para modelos mais complexos.

O pacote computacional SAS ( 1987 ) apresenta quatro tipos de somas de quadrados que diferem quando se trabalha com dados desbalanceados. Dessa forme, serão apresentados os quatro tipos de funções estimávels calculadas pelo SAS.

\section{4. Esti mabilidade}

MILLIKEN \& JOHNSON (1984) definem estimabilidade da seguinte maneira: 
"Um parâmetro ou uma função de parâmetros $f(\beta)$ é estimável se e somente se a estimativa do paràmetro ou da funça doe parâmetroe for invariante com respeito à escolha da soluçăo de mínimos quadrados; isto é, o valor da estimativa o mesmo indepen dente de eecolha da solução das equaçães normais."

Por outro lado, conceito de estimabilidade segundo - Manual do SAS (1987), é dado por:

Fara modelos Iineares, tais como:

$$
y=X \beta+e
$$

que tem $E(Y)=X \beta$, o primeiro passo estimar ou testar os elemen tos de $\beta$ ou certas combinaços lineares dos elementos de $\beta$. Para testar uma funç̃o linear especifice de um determinado $\beta$, istoé, Ls deve-se encontrar uma combinacão Iinear dos $\mathrm{y}^{\prime}$ s que tenha como valor esperado LS. Assim, define-se:

"Iß é estimável se e somente se existir uma combinação li near dos $\mathrm{y}^{\prime}$ " que tenha como valor eeperado LB"

Qualquer combinaç̃o linear dos $\mathrm{y}^{\circ}$ s como, por exemplo $\mathrm{Ky}$, tera $\mathrm{E}(\mathrm{KY})=\mathrm{KX} \beta$. Dessa forma o valor esperado de qualquer combinação linear dos $y^{*}$ s é igual aquela meama combinaça Iinear das linhas de X multiplicado por B. Portanto,

"Lß é estimavel se e somente se uma combinaça linear das Iinhas de $X$, que e igual a L, puder ser encontrada"

As Iinhas de $\mathrm{X}$ formam um conjunto gerador, atraves do qual se pode construir L.

Uma vez que $X$ pode ser reconstruido através de $X=\left[X\left(X^{*} X\right)^{-}\left(X^{-} X\right)\right]$, as linhas de $X^{*} X$ tambem formam um conjunto 
gerador a partir do qual todos os I podem ser construidos. De maneira análoga, as linhas de $\left(X^{\prime} X\right)^{-}\left(X^{\prime} X\right)$ tambem formam um conjunto gerador para L.

Portanto L é estimável quando $L$ é gerado como ume combinaçăo Iinear das linhas de $X, X^{\prime} X$ ou $\left(X^{\prime} X\right)^{-}(X+X)$. Os $L$ gerados devem ter poeto Iinha completo e LB pode ser estimado através de Lb onde $b=(X \times X)^{-} X^{*} y$. Segundo a teoria geral de modelos lineares, Lb é o melhor eetimador não viesado de Lß.

Para testar a hipotese $H_{0}: L \beta=0$, calcula-se a $\mathrm{SQH}_{0}=(\mathrm{Lb})^{-}\left[\mathrm{L}(\mathrm{X} \times)^{-} L^{-1}\right]^{-1}(\mathrm{Lb})$ e constroi-se o teste $\mathrm{F}$ utilizan do o erro apropriado.

\subsubsection{Forma Geral de uma Função Estimâvel}

Como já foi visto anteriormente, inúmeros conjuntos podem ser gerados. O conjunto gerador ldeal é quele que contém o minimo possível de linhas, ou seja, de posto linha completo, e o maximo de elementos nulos.

Através de un exemplo hipotético, será ilutrado como esse conjunto gerador obtido, para tanto, utilizou-se da PROC IML do pacote computacional SAS.

Seja o seguinte esquema experimental para um grupo de experimentos em blocos completos aumentados: 


$\begin{array}{cccc}\mathrm{BlOCO}_{11} & \mathrm{BlOCO}_{21} & \mathrm{Bloc0_{12 }} & \mathrm{Bloc0_{22 }} \\ \mathrm{A} & \mathrm{A} & \mathrm{A} & \mathrm{A} \\ \mathrm{B} & \mathrm{B} & \mathrm{B} & \mathrm{B} \\ \mathrm{a} & \mathrm{d} & \mathrm{a} & \mathrm{d} \\ \mathrm{b} & \mathrm{e} & \mathrm{b} & \mathrm{e} \\ \mathrm{c} & \mathrm{f} & \mathrm{c} & \mathrm{f} \\ & & & \mathrm{L}_{2}\end{array}$

onde,

$$
\begin{aligned}
& A, B \text { são os tratamentos comuns } \\
& a, b, c, d, e, f \text { são os tratamentos regulares; } \\
& b_{11}, b_{21}, b_{12}, b_{22} \text { são os blocos dentro de locais; } \\
& L_{1}, L_{2} \text { são os locais. }
\end{aligned}
$$

Os dados desse experimento encontram-se na Tabela 1 .

Tabela 1. Dados hipotéticos referentes a um grupo de experimentos em blocos completos aumentados

\begin{tabular}{lllllllll}
\hline Local & Bloco & & & & & & & \\
& $B_{1(1)}$ & (A) 107 & (B) 110 & (a) 120 & (b) 130 & (c) 140 \\
Local $_{1}$ & $B_{2(1)}$ & (A) 123 & (B) 130 & (d) 145 & (e) 123 & (f) 110 \\
& $B_{1(2)}$ & (A) 89 & (B) 79 & (a) 78 & (b) 75 & (c) 86 \\
Local $_{2}$ & $B_{2(2)}$ & (A) 97 & (B) 78 & (d) 65 & (e) 76 & (f) 67 \\
\hline
\end{tabular}


A forma geral das funçoses eatimáveis é obtida atra-

vés da expresẽ̃o:

$$
\left[\theta=\left[\left(X^{\prime} X\right)^{92}\left(X^{\prime} X\right)\right] \theta\right.
$$

A partir da matriz $X$ de dimensöes 20 x 31 , obtém-se a matriz $(\mathrm{X}+\mathrm{X})$ que, neste caso será:

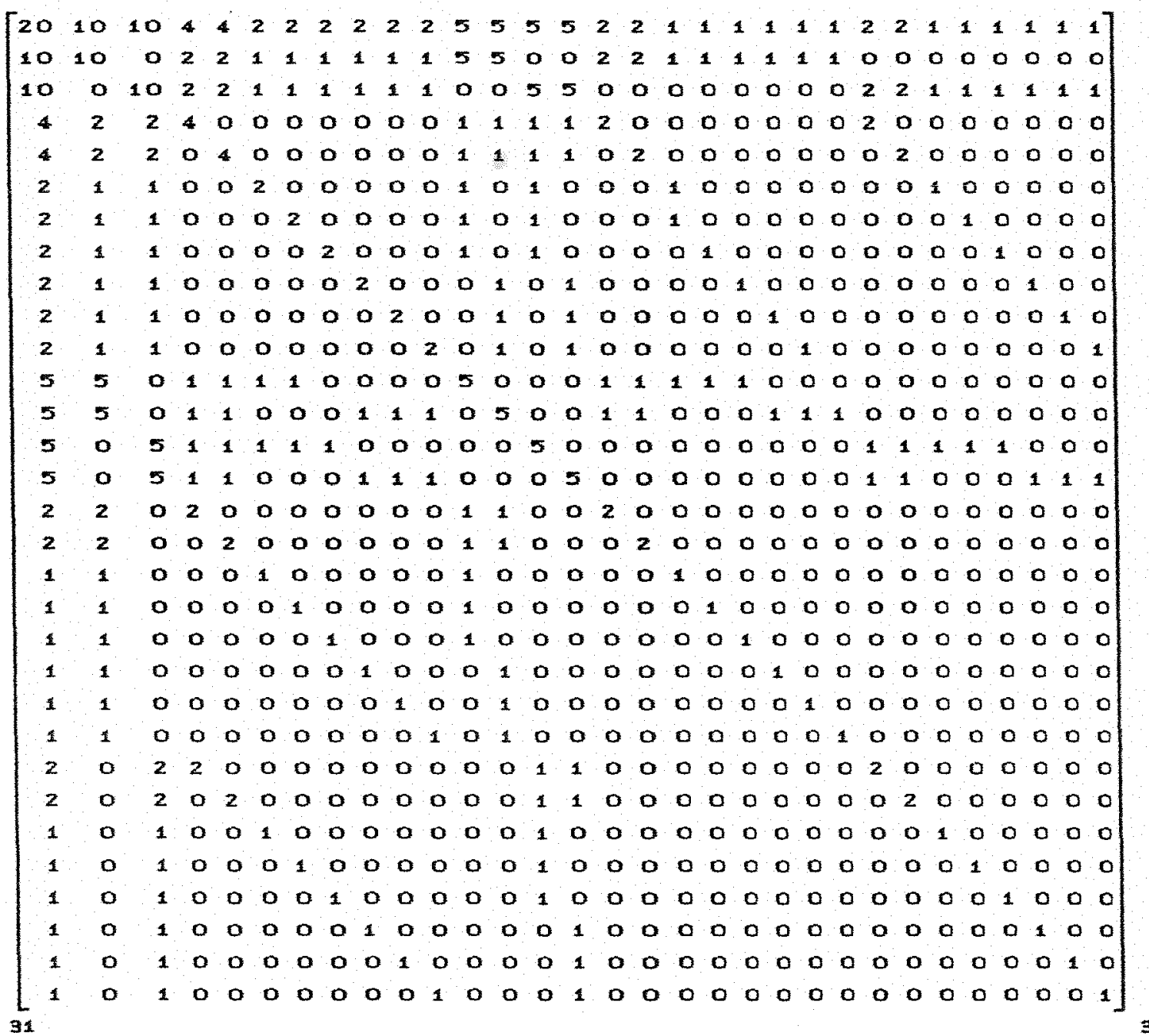

A matriz $\left(\mathrm{X}^{\prime} \mathrm{X}\right)^{\mathrm{g} 2}$ obtida atraves dos seguintes passos: 
a. Toma-se, da matriz X, as colunas linearmente independentes sequencialmente, da esquerda para a direita, e constroi-se uma nova matriz chamada $x_{1}$ de dimensóes $20 \times 31$.

Neste caso, serăo desprezadas as colunas 3 , $11,13,15$ e 23 a 31 da matriz $X$ de delineamento.

b. Calcula-se $\left(X_{1}^{*} X_{1}\right)$ e, a seguir, $\left(X_{1} X_{1}\right)^{-1}$.

c. Para obter-se a matriz $(X+X)^{92}$, colocam-se as colunas da matriz $\left(X_{1} X_{1}\right)^{-1}$ no lugar das colunas linearmente independentes da matriz $\left(X^{*} X\right)$ e zero nas demais colunas.

A matriz L, calculada seguindo esta metodologia é apresentada na Figura 1 .

O pacote computacional SAS (1987) apresenta a forma geral das funçōes estimáveis através da opcra E, acrescentada apos o comando MODEL no procedimento GLM (General Linear Models), cujo resultado é mostrado ne Tabela 2 .

Verifica-se que possivel construir a matriz $L$ à partir da forma geral fornecida pelo SAS (1987). 
Figura 1. Matriz $L=\left(X^{\prime} X\right)^{g^{2}}\left(X^{\prime} X\right)$ para 0 modelo

$$
y_{i j k}=\mu+\lambda_{k}+\alpha_{i}+\beta_{j \mid k}+\gamma_{k i}+\varepsilon_{i j k}
$$

\begin{tabular}{|c|c|c|c|c|c|c|c|c|c|c|c|c|c|c|c|c|c|c|c|c|c|c|c|c|c|c|}
\hline & & & & & & & $\alpha_{i}$ & & & & & & & & & & & & & & & & & & & \\
\hline & 0 & 1 & 0 & 0 & 0 & 0 & o & 0 & o & 1 & 0 & a & o & 1 & $a$ & o & 0 & 0 & 0 & 0 & 0 & 0 & 000000 & 0 & 17 & $L^{1}$ \\
\hline & 1 & -1 & 0 & 0 & 0 & o & 0 & 0 & 0 & 0 & 0 & 1 & 0 & -1 & 0 & 0 & 0 & 0 & 0 & 0 & 0 & 1 & 000000 & 0 & -1 & $I_{2}$ \\
\hline$t$ & 0 & 0 & 0 & 0 & 0 & 0 & 0 & 0 & 0 & 0 & 0 & 0 & o & 0 & 0 & 0 & 0 & 0 & 0 & o & 0 & 0 & 000000 & 0 & o & \\
\hline$c$ & 0 & 0 & 1 & 0 & 0 & 0 & o & o & 0 & -1 & 0 & o & 0 & o & 0 & 0 & o & 0 & 0 & 0 & 0 & o & 100000 & 0 & -1 & IA \\
\hline & 0 & 0 & 0 & 1 & 0 & D & 0 & 0 & 0 & -1 & 0 & 0 & 0 & 0 & 0 & 0 & 0 & 0 & o & 0 & 0 & 0 & 010000 & 0 & -1 & $I s$ \\
\hline$c$ & 0 & 0 & 0 & 0 & 4 & 0 & 0 & 0 & 0 & -1 & 0 & 0 & 0 & 0 & 0 & 0 & 0 & 0 & 0 & 0 & 0 & 0 & 001000 & 0 & -1 & Io \\
\hline 0 & 0 & 0 & 0 & 0 & 0 & 4 & 0 & 0 & 0 & -1 & 0 & 0 & 0 & 0 & 0 & 0 & 0 & 0 & 0 & 0 & 0 & 0 & 000100 & 0 & -1 & $L ?$ \\
\hline 0 & 0 & 0 & 0 & 0 & 0 & 0 & 1 & 0 & 0 & -1 & 0 & o & 0 & 0 & 0 & 0 & 0 & o & $a$ & 0 & 0 & 0 & 000010 & 0. & -1 & Ia \\
\hline 0 & 0 & o & 0 & 0 & 0 & 0 & 0 & 1 & 0 & -1 & 0 & 0 & 0 & o & 0 & 0 & 0 & 0 & 0 & 0 & 0 & 0 & 000001 & 0 & -1 & Lo \\
\hline$c$ & 0 & 0 & 0 & 0 & 0 & 0 & 0 & 0 & 1 & -1 & 0 & $a$ & 0 & 0 & 0 & 0 & 0 & 0 & 0 & 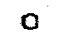 & 0 & 0 & 000000 & 1 & -1 & Lio \\
\hline$c$ & 0 & 0 & 0 & 0 & 0 & 0 & 0 & 0 & 0 & 0 & 0 & 0 & 0 & 0 & 0 & 0 & 0 & 0 & 0 & & s & 0 & 000000 & 0 & 0 & \\
\hline 0 & 0 & $\mathbf{o}$ & 0 & 0 & 0 & 0 & 0 & 0 & 0 & 0 & 1 & -1 & 0 & 0 & $a$ & 0 & 0 & 0 & 0 & 0 & 0 & 0 & 000000 & 0 & 0 & 12 \\
\hline$c$ & 0 & 0 & 0 & 0 & 0 & 0 & 0 & 0 & 0 & 0 & 0 & 0 & 0 & 0 & 0 & 0 & a & $a$ & 0 & 0 & 0 & 0 & 000000 & 0 & 0 & \\
\hline o & 0 & 0 & 0 & 0 & 0 & 0 & 0 & 0 & 0 & 0 & 0 & 0 & 1 & -1 & 0 & 0 & 0 & $a$ & 0 & 0 & 0 & 0 & 000000 & 0 & 0 & L14 \\
\hline 0 & 0 & 0 & 0 & 0 & 0 & o & 0 & 0 & 0 & 0 & 0 & 0 & 0 & 0 & 0 & 0 & 0 & 0 & o & 0 & 0 & 0 & 000000 & 0 & 0 & \\
\hline c & 0 & 0 & 0 & 0 & 0 & 0 & 0 & 0 & 0 & 0 & 0 & 0 & o & 0 & 1 & 0 & 0 & 0 & 0 & 0 & 0 & -1 & -100000 & 0 & 1 & 10 \\
\hline c & 0 & 0 & 0 & 0 & o & 0 & 0 & 0 & 0 & 0 & 0 & 0 & 0 & 0 & 0 & 1 & 0 & 0 & 0 & 0 & 0 & -1 & $0-10000$ & 0 & 1 & L17 \\
\hline 0 & 0 & 0 & 0 & 0 & 0 & 0 & 0 & 0 & 0 & 0 & 0 & 0 & 0 & 0 & 0 & 0 & 1 & 0 & 0 & 0 & 0 & -1 & $00-1000$ & 0 & 1 & Les \\
\hline 0 & 0 & o & 0 & 0 & 0 & 0 & 0 & 0 & 0 & 0 & 0 & 0 & 0 & 0 & 0 & 0 & 0 & 1 & 0 & 0 & 0 & -1 & $000-100$ & 0 & 1 & Lis \\
\hline & o & 0 & 0 & 0 & o & 0 & 0 & 0 & 0 & 0 & 0 & 0 & 0 & 0 & 0 & 0 & 0 & o & 1 & 0 & 0 & -1 & $0000-10$ & 0 & 1 & 20 \\
\hline & 0 & 0 & 0 & 0 & 0 & 0 & $\mathbf{o}$ & 0 & 0 & 0 & $o$ & o & 0 & 0 & 0 & 0 & 0 & 0 & 0 & 2 & o & -1 & $00000-1$ & 0 & 1 & I21 \\
\hline & 0 & 0 & 0 & 0 & 0 & 0 & 0 & 0 & 0 & 0 & 0 & 0 & o & 0 & 0 & 0 & 0 & 0 & 0 & 0 & 1 & -1 & $000000-$ & & 1 & 22 \\
\hline
\end{tabular}

A matriz L, neste caso, terá as dimensóes de 22 1inhas por 31 colunas. 
Tabela 2. Forma geral das funçás estimáveí para o modelo

$$
y_{i j k}=\mu+\lambda_{k}+\alpha_{i}+\beta_{j \mid k}+\gamma_{k i}+\varepsilon_{i j k}
$$

Faràmetros

Coeficientes

$\mu$

$\lambda_{1}$

$\lambda_{2}$

$\alpha 1$

$\alpha 2$

$\alpha_{3}$

$\alpha 4$

as

$\alpha \sigma$

$\alpha 7$

$\alpha B$

Bu(a)

$\beta 2(1)$

$\beta_{1}(2)$

$\beta 2(2)$

$\gamma 11$

$\gamma 12$

$\gamma 13$

$\gamma 14$

$\gamma 15$

$\gamma+0$

$\gamma 17$

$\gamma 18$

$\gamma 21$

$\gamma 22$

$\gamma 23$

$\gamma 24$

$\gamma 25$

126

22?

$\gamma 28$

$$
\begin{gathered}
L_{1} \\
L_{1}^{L_{2}}-L_{2}
\end{gathered}
$$

L4

Ls

Lo

$\mathrm{L7}$

L8

Lo

Lio

$L_{1}-L_{4}-L_{5}-L_{0}-L_{7}-L_{8}-L_{0}-L_{10}$

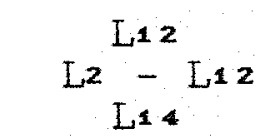

$L_{1}-L_{2}-L_{14}$

L16

Li?

L18

L18

$\mathrm{L} 20$

L21

$\mathrm{L} 22$

$L_{2}-L_{10}-L_{17}-L_{18}-L_{10}-L_{20}-L_{21}-L_{22}$

$L_{4}-L_{16}$

L5 - L17

Lo - L18

L7 - L19

Le - L 20

Lo - L 21

L10- I22

$L_{1}-L_{2}-L_{4}-L_{5}-L_{6}-L_{7}-L_{0}-L_{0}-L_{10}+L_{16}$

$+\mathrm{L}_{17}+\mathrm{L}_{18}+\mathrm{L}_{10}+\mathrm{L}_{20}+\mathrm{L}_{21}+\mathrm{L}_{22}$ 
Atraves da Tabela 3 , pode-se verificar que o núme ro de L's refere-se ao número de coeficientes linearmente independentes do modelo, isto é, representa o posto da matriz ( $\mathrm{X} X \mathrm{X}$ ). 0 número de L's para um efeito correeponde ao número de graus de liberdade para esse determinado efeito; assim, no exemplo dado, tem-se:

\begin{tabular}{|c|c|c|}
\hline $\mathrm{CV}$ & Coeficientes & GL \\
\hline Locel & Lz & 1 \\
\hline Tratamento & $L_{4}, L_{s}, L_{\sigma}, L_{7}, L_{8}, L_{0}, L_{10}$ & 7 \\
\hline Bloco(Local) & $\mathrm{L}_{12}, \mathrm{~L}_{14}$ & 2 \\
\hline Trat * Loc & 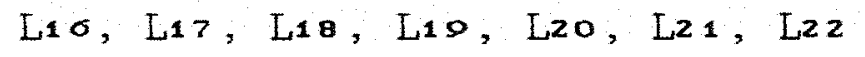 & 7 \\
\hline
\end{tabular}

Atribuindo-se valores para um determinado $\mathrm{Li} \mathrm{e}$ igualando-se os demais a zero, pode-se obter uma determinada funç̃o estimavel. Por exemplo, sendo $\mathrm{l}_{2}=1 \mathrm{e}$, os restantes, iguais a zero, tem-se $\lambda_{1}-\lambda_{2}+\beta_{2}(1)+\beta_{2}(2)+\gamma_{18}-\gamma_{2}$, que representa uma das funçธ̋es que são estimáveis neste delineamento.

$$
\text { Pode-se observar também que tanto } \lambda_{1} \text { como } \lambda_{2} \text {, ñ̃ }
$$
são estimáveis, pois fazendo $L_{2}=1$ e os demais L's iguais a zero

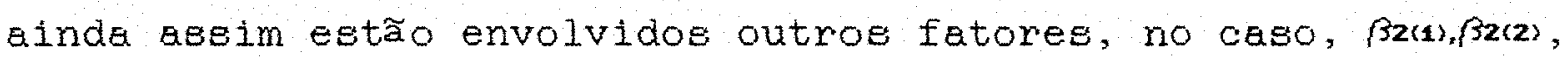
rä rza. Para que não estivessem presentes, lz deveria ser igual a zero, o que é contraditorio; portanto $\lambda_{1}-\lambda_{2}$ não é estimável neste modelo.

Um conjunto básico de funções estimáveis pode ser facilmente obtido quando se faz sucessivamente $L, L 2, \ldots \ldots, L^{n}$ 
igual a um e, os demais, iguais a zero. Esse conjunto básico pode ser encontrado na Tabela 3 .

Tabela 3. Exemplo de um conjunto básico de funçóes estimávels pe ra o modelo $y_{i j k}=\mu+\lambda_{k}+\alpha_{i}+\beta_{j \mid k}+\gamma_{k i}+\varepsilon_{i j k}$

\begin{tabular}{|c|c|c|}
\hline Coefi & cientes & Funçธes estimáveis \\
\hline Lis & $=1$ & $\mu+\lambda_{2}+\alpha_{B}+\beta_{2}(2)+\gamma_{28}$ \\
\hline$L_{2}$ & $=1$ & $\lambda_{1}-\lambda_{2}+\beta_{2(1)}+\beta_{2}(2)+\gamma_{18}-\gamma_{20}$ \\
\hline LA & $=1$ & $\alpha_{1}-\alpha_{0}+\gamma_{21}-\gamma_{28}$ \\
\hline Is: & $=1$ & $\alpha 2-\alpha 8+\gamma 22-\gamma 28$ \\
\hline Lo & $=1$ & $a_{3}-a_{1}+\gamma_{23}-\gamma_{28}$ \\
\hline $\mathrm{LF}$ & $=1$ & $\alpha_{4}-a_{8}+\gamma 24-\gamma 28$ \\
\hline La & $=1$ & $\alpha s-\alpha \theta+\gamma 2 s-\gamma 28$ \\
\hline Lo & $=1$ & $\alpha \sigma-\alpha \theta+\gamma 2 \sigma-\gamma 2 \theta$ \\
\hline I10 & $=1$ & $\alpha z-\alpha \theta+\gamma 27-\gamma 2 \theta$ \\
\hline $\mathrm{I}_{12}$ & $=1$ & $\beta_{1}(1)-\beta 2(1)$ \\
\hline L44 & $=1$ & $\beta 1(2)-\beta 2(2)$ \\
\hline Lio & $=1$ & $\gamma_{11}-\gamma_{10}-\gamma_{21}+\gamma_{20}$ \\
\hline La7 & $=1$ & $\gamma_{12}-\gamma_{18}-\gamma_{22}+\gamma_{28}$ \\
\hline L18 & $=1$ & $\gamma_{13}-\gamma_{18}-\gamma_{23}+\gamma_{20}$ \\
\hline Lis & $=1$ & $\gamma_{1}-\gamma_{10}-\gamma_{24}+\gamma_{20}$ \\
\hline L20 & $=1$ & $\gamma_{15}-\gamma_{18}-\gamma_{25}+\gamma_{28}$ \\
\hline L21 & $=1$ & $\gamma_{10}-\gamma_{10}-\gamma_{20}+\gamma_{28}$ \\
\hline L22: & $=1$ & $\gamma_{17}-\gamma_{18}-\gamma_{27}+\gamma_{28}$ \\
\hline
\end{tabular}


Através da opção SOLUTION, acrescentada após o comendo MODEL, encontrada ne PROC GLM do SAS (1987), é possivel veriflcar quais efeitos são estimáveis, como mostra a Tabela 4.

Tabela 4. Resultados obtidos atraves da opcão SOLUTION ne PROC GLM do SAS.

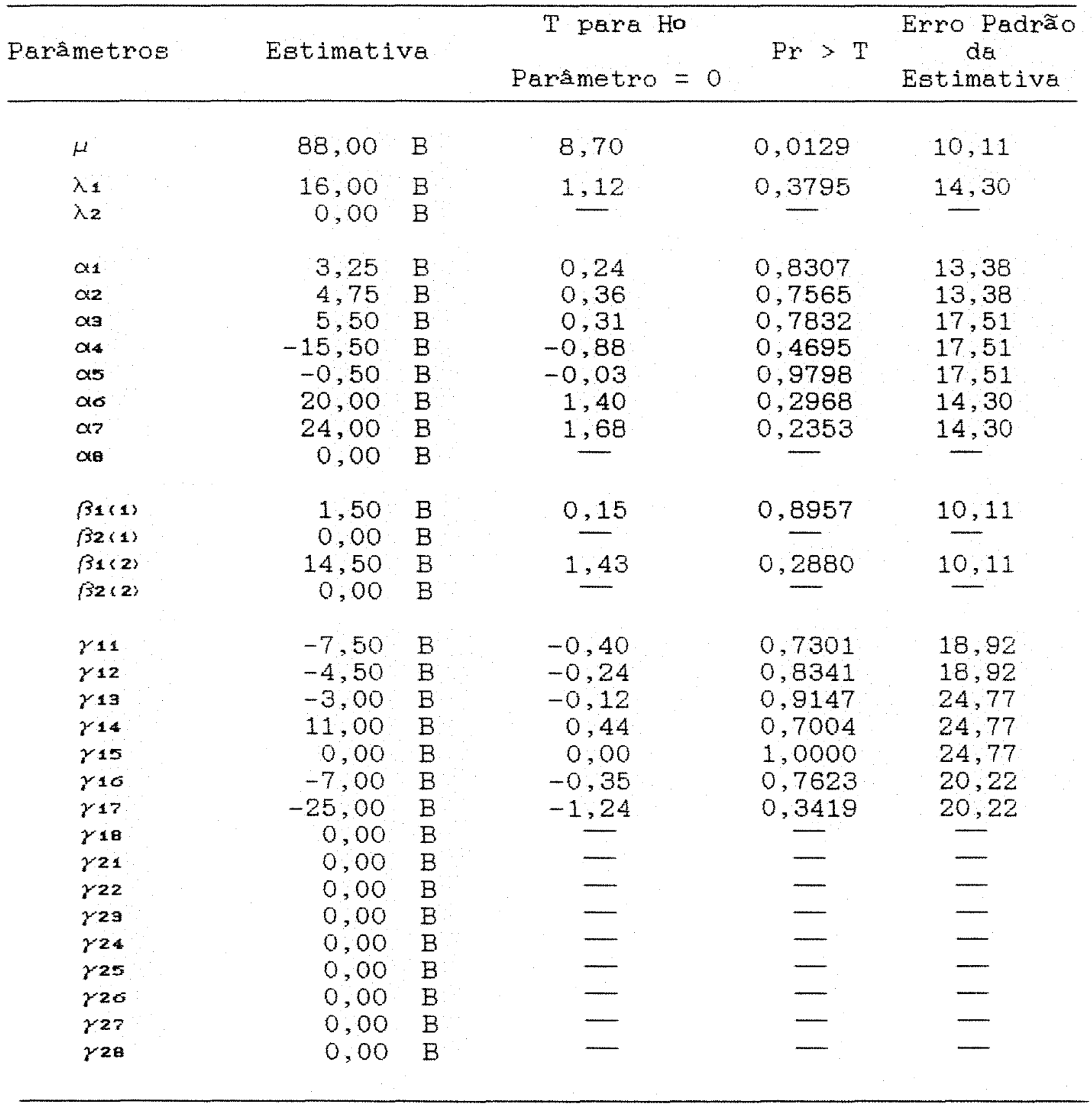


O SAS (1987) imprime uma nota no rodape da tabeia, explicando que, sendo $(X ’ X)$ singular, foi usada uma inversa generalizada para resolver as equaçeo normais.

Embora seja impressa una estimativa de mínimos qua drados para cada parâmetro do modelo, estes, na verdade, não são estimaveie. Isso é indicado atraves de letra B, colocada ao lado da estimativa de mínimos quadrados. As funçós dos parâmetroe, pere os quais estes valores são realmente não viciados, foram apresents dos na Tabela 3 .

\footnotetext{
Assim, $\hat{H}=88,00$ e melhor estimador não viciado para $\mu+\lambda_{2}+\alpha \mathbf{a}+\beta_{2}(2)+\gamma_{28} ; \hat{\lambda}_{1}=16,00$ e melhor estimador não viciado para $\lambda_{1}-\lambda_{2}+\beta_{2}(1)+\beta 2(2)+\gamma_{18}-\gamma_{28}$ e assim sucessivamente, conforme pode ser verificado na Tabela 3.

O erro padrão da estimativa, impresso na Tabela 4 , indica o erro padrão de cada estimador e a estatística t avalia se essas funçơes estimáveie são iguais a zero.

Uma vez definida a forma geral das funções estimáveis, eerão estudadas, a seguir, as funcós estimáveie relativas aos quatro tipos de somas de quadrados fornecidas pelo pacote computacional SAS (1987).
}

\subsection{Funçßes Estimáveis Tipo I}

A Soma de Quadrados Tipo I e as hipóteses a elas associadas são obtidas atraves de um operador "sweep" modificado, usado pare calcular a inversa generalizada gz de $(X ' X)$ e as soluçós das equaçóses normais. Neste tipo de soma de quadrados, cada 
efeito e ajustado apenas para o efeito precedente do modelo. Dessa forma, para o exemplo utilizado neste trabalho, tem-se:

\begin{tabular}{cl}
\hline Efeito & S. Q. Tipo I \\
\hline$\mu$ & $\mathrm{R}(\mu)$ \\
$\lambda$ & $\mathrm{R}(\lambda \mid \mu)$ \\
$\alpha$ & $\mathrm{R}(\alpha \mid \mu, \lambda)$ \\
$\beta$ & $\mathrm{R}(\beta \mid \mu, \lambda, \alpha)$ \\
$\gamma$ & $\mathrm{R}(\gamma \mid \mu, \lambda, \alpha, \beta)$ \\
\hline
\end{tabular}

Segundo IEMMA (1993), as somas de quadrados Tipo I são obtidas atraves do metodo de ordenacão "a priori".

Atraves da opça E1 do comando MODEL na PROC GLM do SAS, obtém-se as funçóes estimáveis do Tipo I, para cada efeito do modelo. Atraves destas e poes vel construir a matriz l para cada um dos efeitos estudados.

Oe reeultados obtidoe atraves da opça El gão moetrados nas Tabelas $5,6,7$ e 8 , para os efeitos de Local, Tratamento, Bloco(Local) e Trat*Local, respectivamente. 
Tabela 5. Funcoses estimáveis do Tipo I para o efeito de Local, ge gundo o modelo

$$
y_{i j k}=\mu+\lambda_{k}+\alpha_{i}+\beta_{j \mid k}+\gamma_{k i}+\varepsilon_{i j k}
$$

\begin{tabular}{|c|c|c|}
\hline \multirow{2}{*}{$\frac{\text { Parametros }}{\mu}$} & \multicolumn{2}{|c|}{ Coeficientes } \\
\hline & & 0 \\
\hline$\lambda_{1}$ & & $I_{2}$ \\
\hline$\lambda_{2}$ & -1 & I2 \\
\hline$\alpha 1$ & & 0 \\
\hline$\alpha 2$ & & 0 \\
\hline$\alpha 3$ & & 0 \\
\hline$\alpha 4$ & & 0 \\
\hline as & & 0 \\
\hline$\alpha \sigma$ & & 0 \\
\hline$\alpha z$ & & 0 \\
\hline$\alpha 8$ & & 0 \\
\hline$\beta 1\{1\}$ & $1 / 2$ & I2 \\
\hline$\beta 2(1)$ & $1 / 2$ & $I_{2}$ \\
\hline$\beta_{1}(2)$ & $-1 / 2$ & $I_{2}$ \\
\hline$\beta_{2}(2)$ & $-1 / 2$ & $\mathrm{~L}_{2}$ \\
\hline$\gamma 11$ & $2 / 10$ & L2 \\
\hline$\gamma 12$ & $2 / 10$ & $\mathrm{~L}_{2}$ \\
\hline$\gamma 13$ & $1 / 10$ & $I_{2}$ \\
\hline$\gamma 14$ & $1 / 10$ & $I_{2}$ \\
\hline$\gamma 15$ & $1 / 10$ & $\mathrm{~L}_{2}$ \\
\hline$\gamma 16$ & $\pm / 10$ & $I_{2}$ \\
\hline$\gamma 17$ & $1 / 10$ & $I_{2}$ \\
\hline$\gamma 18$ & $1 / 10$ & $\mathrm{Lz}$ \\
\hline$r 21$ & $2 / 10$ & L2 \\
\hline$\gamma 22$ & $2 / 10$ & Iz \\
\hline$\gamma / 23$ & $1 / 10$ & $\mathrm{~L}_{2}$ \\
\hline$\gamma 24$ & $1 / 10$ & $\mathrm{I} 2$ \\
\hline$\gamma 25$ & $1 / 10$ & $\mathrm{I}_{2}$ \\
\hline$\gamma 26$ & $1 / 10$ & $L_{2}$ \\
\hline$\gamma 2 z$ & $1 / 10$ & $I_{2}$ \\
\hline$\gamma 28$ & $1 / 10$ & L2 \\
\hline
\end{tabular}


Tabela 6. Funçōes estimáveis do Tipo I para o efeito de Tratamento, segundo o modelo

$$
y_{i j k}=\mu+\lambda_{k}+\alpha_{i}+\beta_{j \mid k}+\gamma_{k i}+\varepsilon_{i j k}
$$

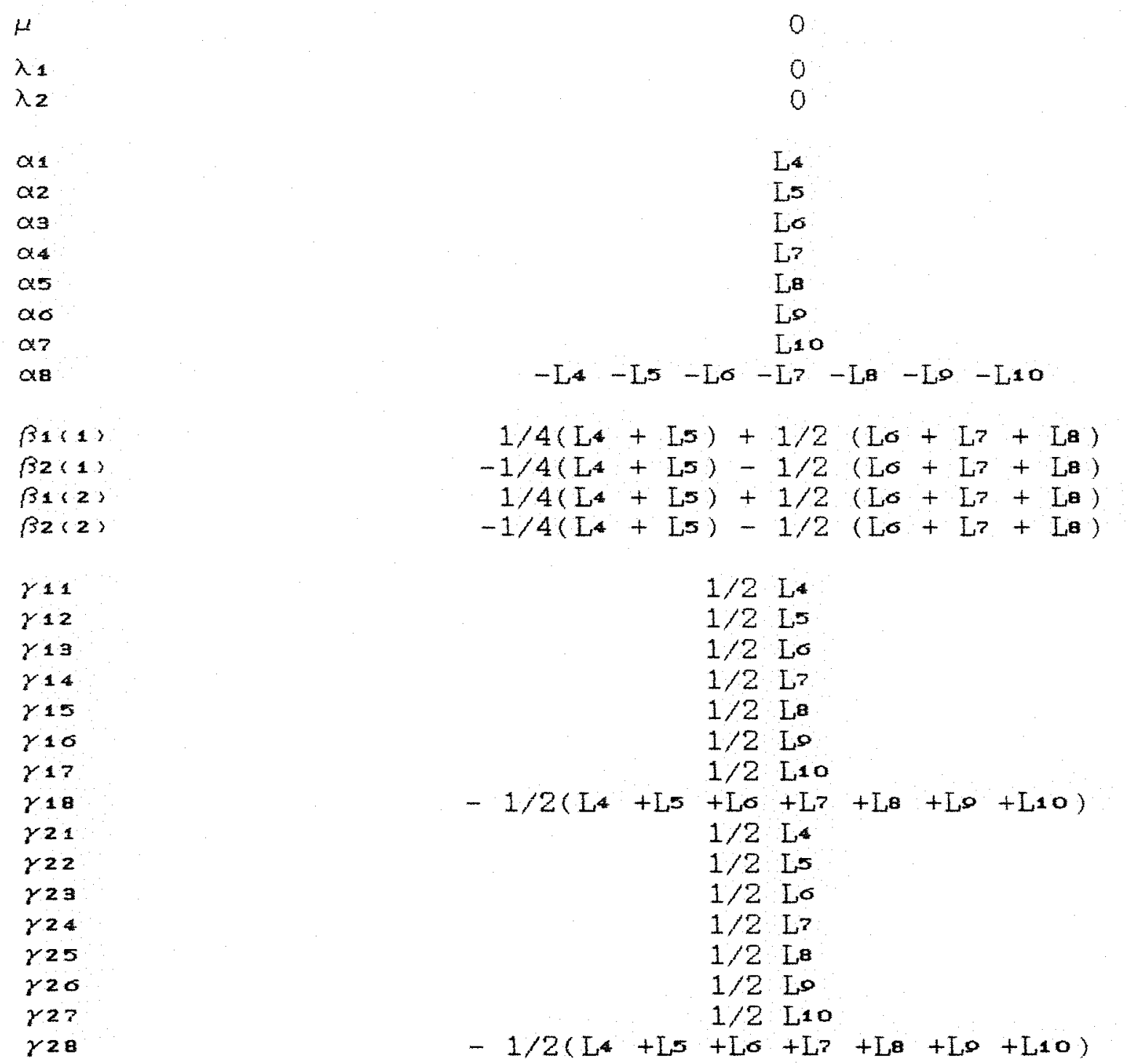


Tabela 7. Funções estimáveis do Tipo I para o efeito de Bloco(Local), segundo o modelo

$$
y_{i, j k}=\mu+\lambda_{k}+\alpha_{i}+\beta_{j \mid k}+\gamma_{k i}+\varepsilon_{i j k}
$$

Paràmetros

Coeficientes

$\mu$ 0

$\lambda_{1}$

$\lambda 2$

0

$\alpha 1$

$\alpha 2$

$\alpha 3$

$\alpha$

$\alpha 5$

ar

$a r$

$\alpha 8$

B1(1)

$\beta 2(1)$

B1(2)

$\beta 2(2)$

$\gamma 11$

$\gamma 12$

$\gamma 13$

$\gamma 14$

ras

$\gamma 10$

Y17

$\gamma 18$

$\gamma 21$

$\gamma 22$

$\gamma 23$

$\gamma^{24}$

725

$\gamma 20$

$\gamma 27$

r2a

\begin{tabular}{|c|c|}
\hline & 0 \\
\hline & 0 \\
\hline & 0 \\
\hline & 0 \\
\hline & 0 \\
\hline & 0 \\
\hline & 0 \\
\hline & 0 \\
\hline & 0 \\
\hline & 0 \\
\hline & 0 \\
\hline & $L_{12}$ \\
\hline & $-L_{12}$ \\
\hline & $L_{14}$ \\
\hline & $-\mathrm{L}_{14}$ \\
\hline & 0 \\
\hline & 0 \\
\hline $\begin{array}{l}1 / 10 \\
1 / 10\end{array}$ & \\
\hline $\begin{array}{l}1 / 10 \\
1 / 10\end{array}$ & $\left(\begin{array}{l}\left(L_{12}-L_{14}\right) \\
\left(L_{12}-L_{14}\right)\end{array}\right.$ \\
\hline $1 / 10$ & $\left(-L_{12}+L_{14}\right)$ \\
\hline $1 / 10$ & $\left(-L_{12}+L_{14}\right)$ \\
\hline $1 / 10$ & $(-L 12+L 14)$ \\
\hline & $\begin{array}{l}0 \\
0\end{array}$ \\
\hline $1 / 10$ & $\left(-L_{12}+L_{14}\right)$ \\
\hline $1 / 10$ & $\left(-L_{12}+L_{14}\right)$ \\
\hline $1 / 10$ & $(-\operatorname{Li2}+\operatorname{L14})$ \\
\hline $1 / 10$ & $\left(L_{12}-L_{14}\right)$ \\
\hline $1 / 10$ & $\left(L_{12}-L_{14}\right)$ \\
\hline $1 / 10$ & $\left(L_{12}-L_{14}\right)$ \\
\hline
\end{tabular}


Tabela 8. Funçoes estimáveis do Tipo I para o efeito da interaça Trat*Iocal, segundo o modelo

$$
y_{i j k}=\mu+\lambda_{k}+\alpha_{i}+\beta_{j \mid k}+\gamma_{k i}+\varepsilon_{i j k}
$$

Parametros Coeficientes

\begin{tabular}{|c|c|c|}
\hline$\mu$ & & 0 \\
\hline$\lambda_{1}$ & & 0 \\
\hline$\lambda 2$ & & 0 \\
\hline$\alpha i$ & & 0 \\
\hline$\alpha z$ & & 0 \\
\hline$\alpha 3$ & & 0 \\
\hline$\alpha 4$ & & 0 \\
\hline as & & 0 \\
\hline$\alpha<$ & & 0 \\
\hline$\alpha z$ & & 0 \\
\hline$\alpha \mathbf{s}$ & & 0 \\
\hline$\beta_{1}(1)$ & & 0 \\
\hline$\beta 2(1)$ & & 0 \\
\hline$\beta_{1}(2)$ & & 0 \\
\hline$\beta 2(2)$ & & 0 \\
\hline$\gamma_{11}$ & & L16 \\
\hline$\gamma 12$ & & Lit \\
\hline$\gamma 13$ & & Lis \\
\hline$\gamma_{14}$ & & L10 \\
\hline ras & & 120 \\
\hline$\gamma 10$ & & L21 \\
\hline$\gamma 17$ & & $\mathrm{~L} 22$ \\
\hline$\gamma_{10}$ & $-L_{10}-L_{13}-I_{10}$ & $-I_{10}-I_{20}-I_{21}-I_{22}$ \\
\hline$\gamma 21$ & & - Lio \\
\hline$\gamma 22$ & & $-L_{17}$ \\
\hline$r 23$ & & - L10 \\
\hline$\gamma 24$ & & - L10 \\
\hline$\gamma 25$ & & $-\mathrm{I} 20$ \\
\hline 220 & & $-L_{21}$ \\
\hline$r 27$ & & $-\bar{I} 22$ \\
\hline$\gamma 20$ & $L_{10}+I_{17}+L_{18}$ & $+L_{10}+I_{20}+L_{21}+I_{22}$ \\
\hline
\end{tabular}


Para que se tenha uma visão geral das hipóteses testadas, estas também podem eer descritas como mostra a Tabela 9.

Tabela 9. Hipoteses testadas atraves da Soma de Quadrados Tipo I.

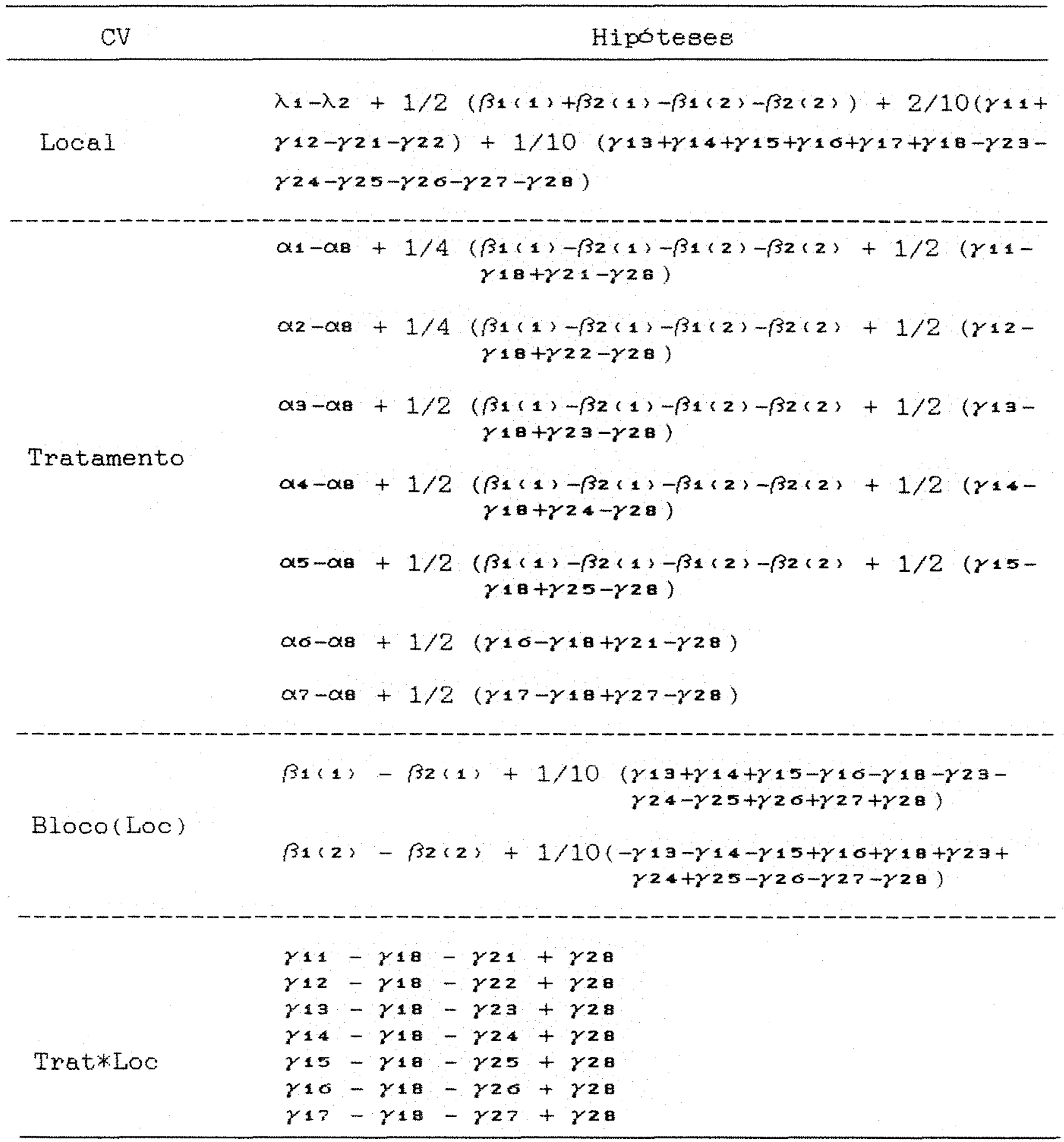


Baseando-se nas hipoteses descritas anteriomente, a análise de variancia, apresentando as somas de quadrados Tipo I e dada a Beguir:

\begin{tabular}{llrr}
\hline CV & GL & \multicolumn{1}{c}{ SQ } & QM \\
\hline Locais & 1 & 10035,20 & 10035,20 \\
Tratamentos & 7 & 694,55 & 99,22 \\
Blocos (Loc) & 2 & 346,33 & 173,16 \\
Trat*Loc & 7 & 1242,47 & 177,50 \\
Residuo & 2 & 24,25 & \\
\hline
\end{tabular}

Deve-se ressaltar que a inclusão dos resultados da análise de variancia terão aqui apenae um carater ilustrativo. Com o decorrer da apresentaça do texto, esses aspectos serão discutidos.

Como já fol comentado anteriormente, na Soma de Quadrados do Tipo I cada efeito é ajustado em relaça ao efeito precedente; portanto, é importante a ordem de entrada dos efeitos no modelo. Uma vez que o SAS (1987) utiliza apenas as linhas linearmente independentes de maneira sequencial, para que se possa testar o efeito de local, no exemplo dado, as colunas da matriz X para esse efelto deverão estar posicionadas ao lado da coluna de $\mu$. Fazendo uma inversão na ordem dos efeltos, como por exemplo,

$$
y_{i j k}=\mu+\beta_{j \mid k}+\lambda_{k}+\alpha_{i}+\gamma_{k i}+\varepsilon_{i j k}
$$

ñ̃ é possível testar Local, pois as colunas referentes a esse 
efeito não são Iinearmente independentes das precedentes.

A matriz $L$, obtida atravé da opção $E$, acrescentada após o comando MODEL, na PROC GLM do SAS (1987), será apresentada a seguir como Figura 2. A Tabela 9 apresenta um conjunto bási co de funçães estimáveis para o modelo acima. Ele foi obtido atribuindo-se valores iguais a um para cada l e zero para os demais. Outros conjuntos básicos podem ser obtidos dando-se outros valores para os $\mathrm{L}^{3} \mathrm{~s}$.

Figura 2. Matriz L para o modelo

$$
y_{i j k}=\mu+\beta_{j \mid k}+\lambda_{k}+\alpha_{i}+\gamma_{k i}+\varepsilon_{i j k}
$$

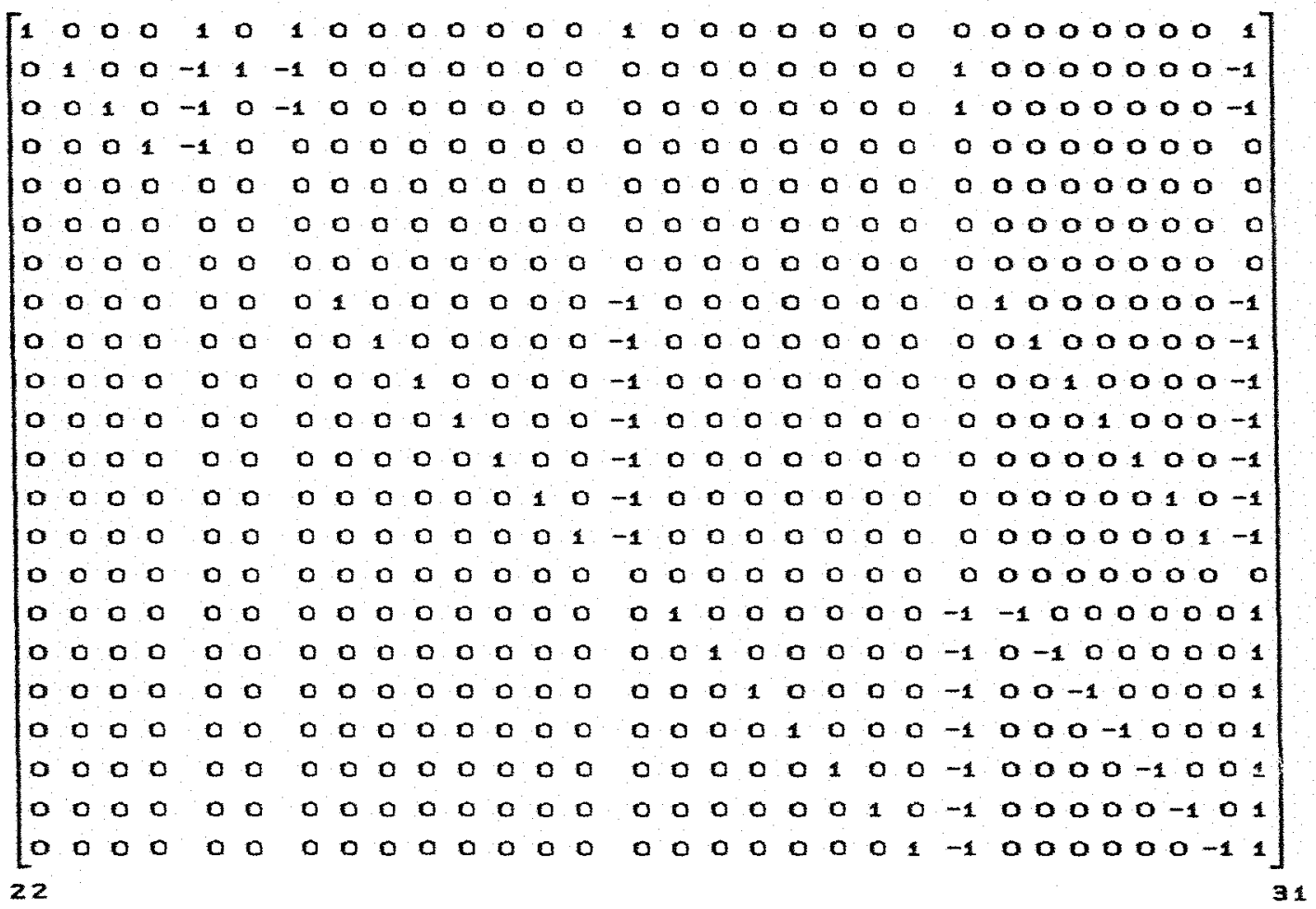


Tabela 10. Um conjunto básico de funçðes estimáveis para o mode$10 \quad y_{i j k}=\mu+\beta_{j \mid k}+\lambda_{k}+\alpha_{i}+\gamma_{k i}+\varepsilon_{i j k}$

\begin{tabular}{|c|c|c|}
\hline Coef & icientes & Funcröes estimáveis \\
\hline L, & $=1$ & $\mu+\lambda_{2}+\alpha_{\theta}+\beta z(z)+\gamma 2 \theta$ \\
\hline $\mathrm{I}_{2}$ & $=1$ & $\lambda_{1}-\lambda_{2}+\beta_{1}(1)+\beta_{2}(2)+\gamma_{18}-\gamma_{28}$ \\
\hline $\mathrm{L} \mathbf{a}$ & $=1$ & $\lambda_{1}-\lambda_{2}+\beta_{2}(1)-\beta_{2}(2)+\gamma_{10}-\gamma_{20}$ \\
\hline La & $=1$ & $\alpha_{1}-\alpha_{8}+\gamma_{21}-\gamma_{28}$ \\
\hline Lo & $=1$ & $\alpha z-\alpha 8+\gamma 2 z-\gamma 28$ \\
\hline Lio & $=1$ & $\alpha_{3}-\alpha_{\theta}+\gamma_{23}-\gamma_{28}$ \\
\hline L11 & $=1$ & $\alpha_{4}-\alpha_{8}+\gamma_{24}-\gamma_{28}$ \\
\hline Li2 & $=1$ & $\alpha_{5}-\alpha_{8}+\gamma 25-\gamma 28$ \\
\hline L13 & $=1$ & $\alpha \theta-\alpha \theta+\gamma 20-\gamma 2 \theta$ \\
\hline L14 & $=1$ & $a_{7}-\alpha \theta+\gamma 27-\gamma 28$ \\
\hline Lio & $=1$ & $\gamma_{11}-\gamma_{18}-\gamma_{21}+\gamma_{28}$ \\
\hline$L_{\mathbf{1}}$ & $=1$ & $\gamma_{12}-\gamma_{18}-\gamma_{22}+\gamma_{2 \theta}$ \\
\hline LiB & $=1$ & $\gamma_{13}-\gamma_{18}-\gamma_{23}+\gamma_{28}$ \\
\hline Lis & $=1$ & $\gamma_{14}-\gamma_{18}-\gamma_{24}+\gamma_{28}$ \\
\hline L20 & $=1$ & $\gamma_{1 s}-\gamma_{10}-\gamma_{2 s}+\gamma_{20}$ \\
\hline L21 & $=1$ & $\gamma_{10}-\gamma_{10}-\gamma_{20}+\gamma_{20}$ \\
\hline$I 22$ & $=1$ & $\gamma_{12}-\gamma_{18}-\gamma_{27}+\gamma_{28}$ \\
\hline
\end{tabular}




\section{4. 3. Funçốes Estimáveis Tipo II}

$\mathrm{Na}$ Soma de Quadrados Tipo II, neste modelo, cada efeito é ajustado pare todos os demais efeitos, exceto para $\mathrm{s}$ interacão. Para o modelo adotado tem-se:

\begin{tabular}{cl}
\hline Efeito & S. Q. Tipo II \\
\hline$\lambda$ & $R(\lambda \mid \mu, \alpha, \beta)$ \\
$\alpha$ & $R(\alpha \mid \mu, \lambda, \beta)$ \\
$\beta$ & $R(\beta \mid \mu, \lambda, \alpha)$ \\
$\gamma$ & $R(\gamma \mid \mu, \lambda, \alpha, \beta)$ \\
\hline
\end{tabular}

Esta soma de quadrados propicia (para modelos de regressão e efeitos principais) uma hipotese de posto máximo (MRH) para cada efeito que não envolva os parâmetros dos outros efeitos.

Não possivel obter um teste de hipotese para um efeito principal, livre de outros efeitos, em modelos que envolvam interaça e efeitos aninhados, a nãa ser que sejam feitas algumas restriçóes paramétricas "a priori". Iato pode ser verificado na Ta bela 11 e o resultado da análise de variancia, para as hipóteses já descritas, é apresentado na Tabela 12. 
Tabela 11. Hipóteses testadas na soma de quadrados Tipo II para - mode 10

$$
\mathrm{y}_{i j k}=\mu+\lambda_{k}+\alpha_{i}+\beta_{j \mid k}+\gamma_{k i}+\varepsilon_{i j k}
$$

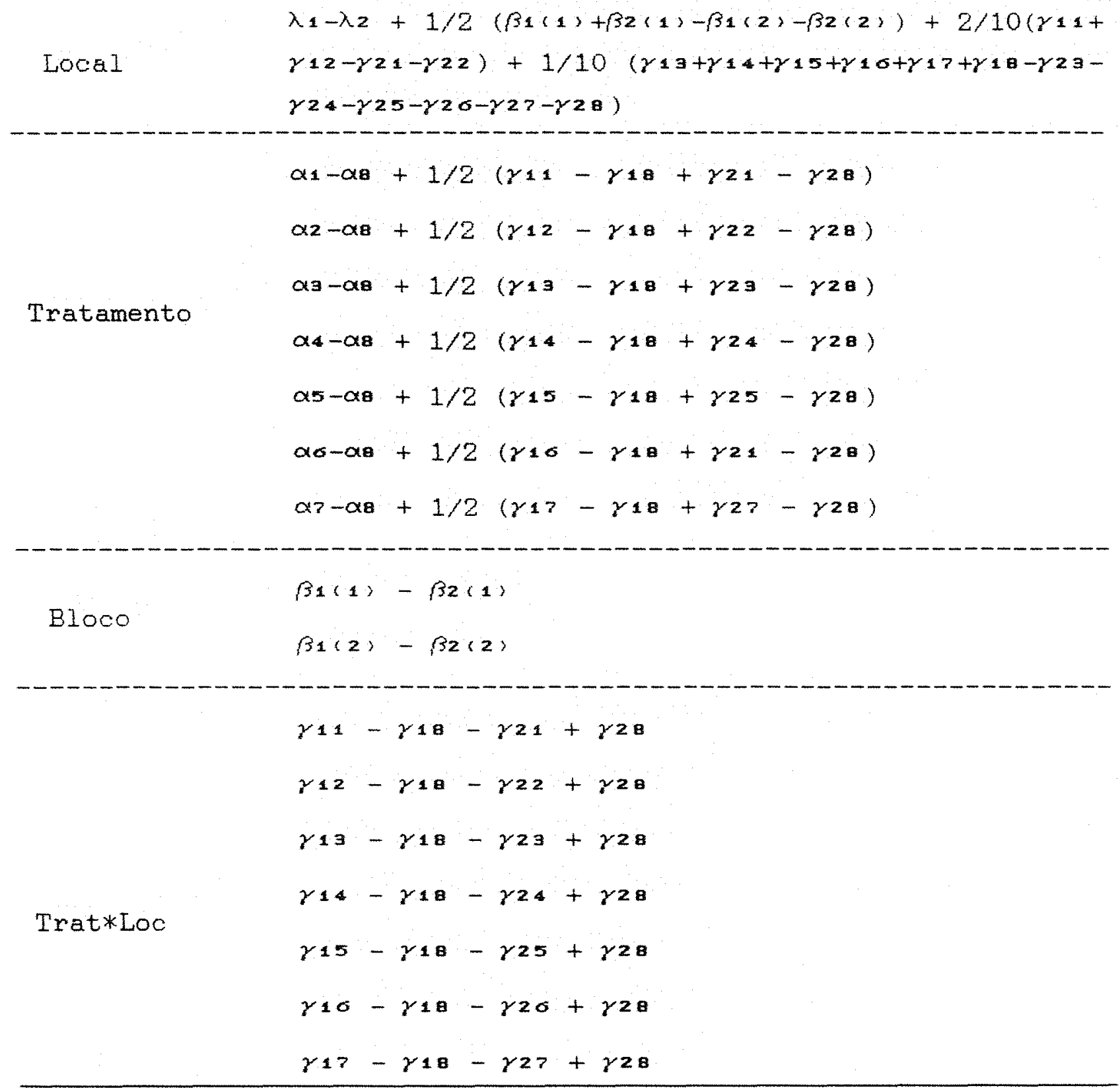


Tabela 12. Análise de variancia apresentando as somas de quadrados Tipo II para o modelo

$$
y_{i j k}=\mu+\lambda_{k}+\alpha_{i}+\beta_{j \mid k}+\gamma_{k i}+\varepsilon_{i j k}
$$

\begin{tabular}{llrl}
\hline CV & GL & \multicolumn{1}{c}{ SQ } & QM \\
\hline Locais & 1 & 10035,20 & 10035,20 \\
Tratamentos & 7 & 925,67 & 132,24 \\
Blocos (Loc) & 2 & 336,25 & 168,13 \\
Trat*Loc & 7 & 1242,47 & 177,50 \\
Residuo & 2 & 24,25 & \\
\hline
\end{tabular}

Segundo o Manual do SAS (1987) a Soma de Quadrados Tipo II e adequade para:

- qualquer modelo balanceado;

- qualquer modelo de efeito principal;

- qualquer modelo de regressão;

- modelos que não possuem efeitos contidos em ou tros efeitos.

\subsubsection{Funçỡes estimáveis Tipo III.}

As hipoteses Tipo III gão construidas a partir da forma geral das funcōes estimáveis. Elas podem ser obtidas atraves do método de quadrados de médias ponderadas, $Y_{2}$, de YATES (1934); de mínimos quadrados completos, $05_{1}$, de OVERALL \& SPIEGEL (1969); - da inversa da parte inversa de SEARLE (1971), entre outros. Assim a notaça $R$ () para o exemplo dado, será: 


\begin{tabular}{ll}
\hline Efeito & S. Q. Tipo III \\
\hline$\mu$ & $R(\dot{\mu} \mid \dot{\lambda}, \dot{\alpha}, \dot{\beta}, \dot{\gamma})$ \\
$\alpha$ & $R(\dot{\lambda} \mid \dot{\mu} \dot{\alpha}, \dot{\beta}, \dot{\gamma})$ \\
$\beta$ & $R(\dot{\alpha} \mid \dot{\mu}, \dot{\lambda}, \dot{\beta}, \dot{\gamma})$ \\
$\gamma$ & $R(\dot{\beta} \mid \dot{\mu}, \dot{\alpha}, \dot{\gamma})$ \\
\hline
\end{tabular}

Para construir a hipotese de um efeito qualquer (H1), deve-se seguir as seguintes etapas:

a.) Igualar a zero todos os coeficientes da forma geral das funçes estimáveis, exceto aquelas referentes a $\mathrm{H} 1$ e os efeitos que contém H1. Se no modelo adotado, um efeito está contido em outro, deve-se passar à etapa seguinte.

b.) Sendo necesgário, criar novos gímbolos para compor expressós no bloco Hl a fim de obter uma forma mais simples para os coeficientes de H1.

c.) Igualar todos os coeficientes simbóicoe fora do bloco H1 a ume função linear doo simbolos do bloco Hl, a fim de que a hipotese de $H 1$ seja ortogonal às hipoteses associadas aos efeitoe que contem $\mathrm{H} 1$.

Seguindo-se esse procedimento, obtem-se os results dos apresentados na Tabela 14 . 
A análize de variáncia referente à hipóteses da Tabela 14, вão apresentadas na Tabela 13.

Tabela 13. Análise de variância apresentando as somas de quadrados Tipo III para o modelo

$$
y_{i j k}=\mu+\lambda_{k}+\alpha_{i}+\beta_{j \mid k}+\gamma_{k i}+\varepsilon_{i j k}
$$

\begin{tabular}{llrr}
\hline CV & GL & \multicolumn{1}{c}{ SQ } & \multicolumn{1}{c}{ QM } \\
\hline Locais & 1 & 10560,02 & 10560,02 \\
Tratamentos & 7 & 925,67 & 132,24 \\
Blocos(Loc) & 2 & 336,25 & 168,13 \\
Trat*Loc & 7 & 1242,47 & 177,50 \\
Resi duo & 2 & 24,25 & \\
\hline
\end{tabular}


Tabela 14. Hipóteses testadas para a soma de quadrados T1po considerando o modelo

$$
y_{i j k}=\mu+\lambda_{k}+\alpha_{i}+\beta_{j \mid k}+\gamma_{k i}+\varepsilon_{i j k}
$$

CV

Hipoteses

Tratamento

$\lambda_{1}-\lambda_{2}+1 / 2\left(\beta_{1}(1)+\beta_{2}(1)-\beta_{1}(2)-\beta_{2}(2)\right)+1 / 8\left(\gamma_{1}\right)$

$\operatorname{Local}$

$\gamma_{12}+\gamma_{13}+\gamma_{14}+\gamma_{15}+\gamma_{10} \sigma \gamma_{17}+\gamma_{18}-\gamma_{21}-\gamma_{22}-\gamma_{23}-\gamma_{24}-\gamma_{25}-$ $\gamma 20-\gamma 27-\gamma 28)$

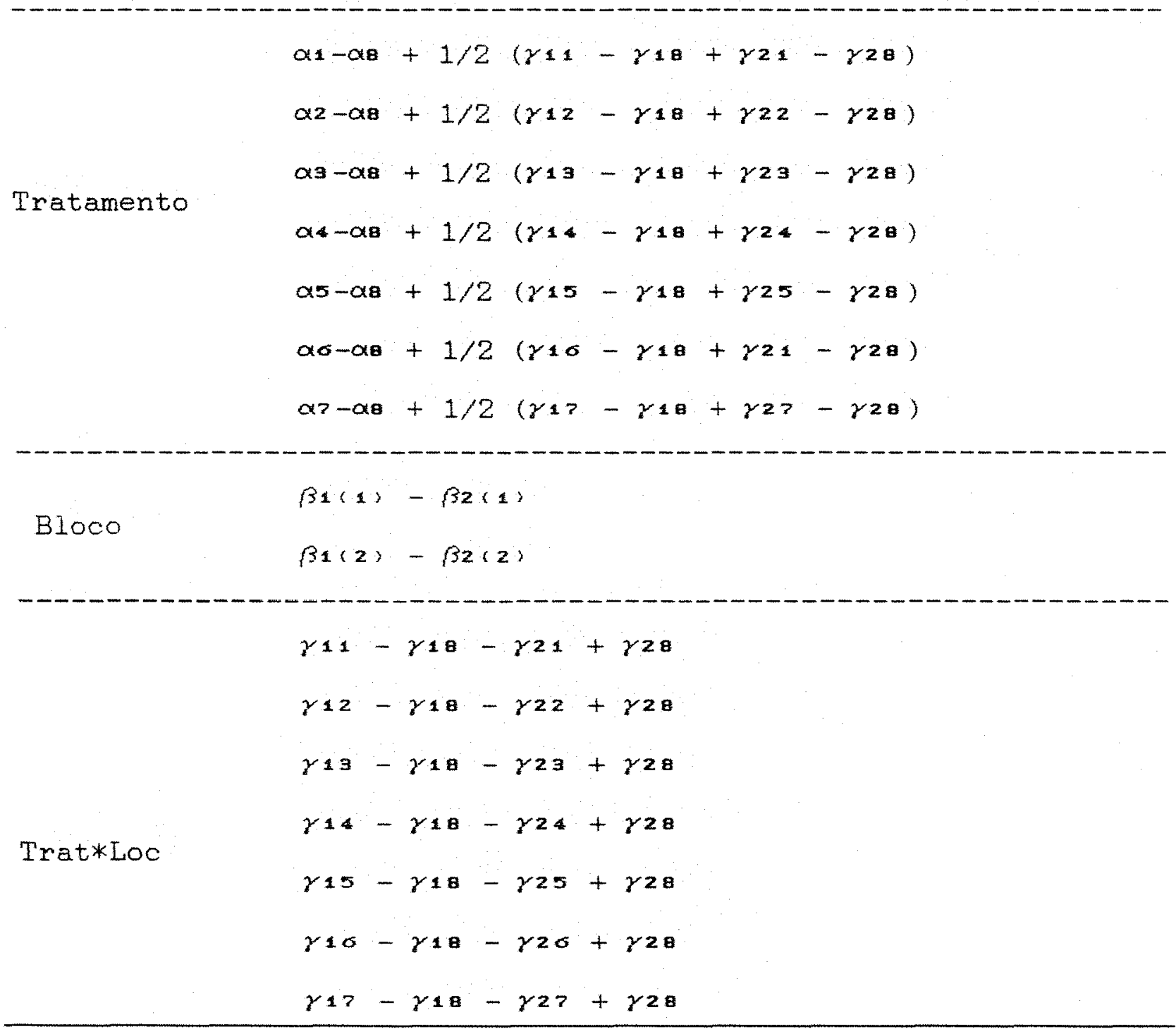




\subsubsection{Funções estimáveis Tipo IV}

Segundo IEMMA (1992, 1993), não existindo caselas vazias as somas de quadrados Tipo IV são similares às do Tipo III. Havendo caselas vazias elas são, em geral, diferentes e se referem a hipoteses distintas. Estas ñ̃ eã unicas pois dependem do número e da posição das casela vazias.

Uma vez que os dados analisados no presente trabaTho referem-se a blocos completos, as hipóteses testadas Tipo IV $e$ as respectivas somas de quadrados não diferem das do Tipo III.

\subsection{Esperança do Quadrado Médio}

De acordo com o Manuel do SAS (1987), Esperancas do Quadrado Médio (E [QM]) são expressões algébricas que especificam quais funçőes doe parâmetros do modelo são estimadas pelo quadrado médio, são resultados das partiços das somas de quadrados. Geralmente essas $E$ [QM] são funcóes lineares dos elementos representando:

a.) a variancia do erro

b.) funçôes de variâncias de efeitos aleatorios

c.) funçōes de somas de quadrados e formas quadráticas de efeitos fixos.

o principio básico do teste $F$ de um conjunto de pe râmetros de efeito fixo postula que a $E$ [QM] para o denominador contenha ume funça linear das variancias de efeitos aleatórios, 
enquanto que a $\mathrm{E}$ [QM] do numerador contenha as mesmas funçơes das variâncias, acrescidas da forma quadrática dos parámetros a serem testados. Se essa relaça não existir, o teste passa a ser aproximado.

Para modelos de efeitos fixos, o teste é efetuado através da variância residual.

Uma soma de quadrados pode sempre ser representade atravé de forma quadrática

$$
Q=y^{*} A y
$$

onde y é vetor de observaçôes e A é uma matriz de constantes, si métrica, escolhida apropriadamente.

$$
\begin{aligned}
& \text { Sabe-se tambem que } \\
& \qquad E\left[\mathrm{y}^{-\mathrm{Ay}}\right]=\operatorname{Tr}[\mathrm{PI}] \sigma^{2}+\theta^{-X} \mathrm{XX} \theta
\end{aligned}
$$

onde:

$\mathrm{P}=\mathrm{XX}^{+}$, idempotente, onde $\mathrm{X}^{+}$é a inversa de Moore-Penrose

$\theta \in$ o vetor de parametros

As esperancas dos quadrados médios são calculadas da seguinte forma:

$$
\begin{aligned}
& \text { Seja o modelo } \\
& y=X_{0} \beta_{0}+X_{i} \beta_{1}+\ldots \ldots+X_{k} \beta_{k}+\varepsilon,
\end{aligned}
$$

onde:

$\beta_{0}$ represente o efeito fixo, $e$

$\beta_{1} \ldots \ldots \beta_{k}$ representam os efeitos aleatorios

Assumem-se os efeitos aleatorios como independentes e normalmente distribuidos. Para algum L no espaco linha de 


$$
X=\left(x_{0}\left|x_{1}\right| x_{z}|\cdots \ldots| x_{k}\right)
$$

tem-se,

$E\left[S Q_{L}\right]=\beta_{0} C_{0} C_{0} \beta_{0}+S Q Q\left(C_{1}\right) \sigma_{k}^{2}+\ldots \ldots+S Q Q\left(C_{k}\right) \sigma_{k}^{2}+$ posto $(L) \sigma_{e}^{2}$ onde $Q(C)$ é a forma quadrática de $C$, com a mesma dimensão de L, sendo esta uma partiç̃o de $X$. Alem disso, $C=M L$, onde $M$ é a inver sa de Cholesky e L $\mathrm{L}$ uma funça estimável.

Para os modelos mistos, a E [QM] pode ser obtida a travé do comando RANDOM na PROC GLM do SAS (1987), sendo necessário especificar quais efeitos do modelo eão aleatórios. A opção $Q$, acrescentada depois do comando RANDOM calcula os coeficientes da forma quadrática aseoclada ao efelto fixo.

No modelo apresentado neste estudo, considerou-se $\alpha_{i}$ com efeito fixo e os demais parámetros com efeito aleatorio e, através do comando RANDOM, foram obtidas as $\mathrm{E}$ [QM] e as respectivas formas quadraticas para os quatro tipos de somas de quadrados, que são apresentadas nas tabelas 15,16 e 17. 
Tabela 15. Esperancas dos Quadrados Médios para a Soma de Quadrados Tipo I.

\begin{tabular}{|c|c|c|c|c|c|c|}
\hline $\mathrm{CV}$ & & $E$ & {$[\mathrm{QM}]$} & & & \\
\hline$L$ & $\sigma^{2}+10,00$ & $\sigma_{L}^{2}$ & & $+5,00 \alpha^{2}$ & $+1,40$ & $\alpha_{\mathrm{TL}}^{2}$ \\
\hline$T$ & $\sigma^{2}$ & & $+Q(t)$ & $+0,43 \sigma^{2}$ & $+1,22$ & $\sigma_{T L}^{2}$ \\
\hline$B(L)$ & $\alpha^{2}$ & & & $+3,50 \sigma_{B}^{2}$ & $+0,30$ & $\sigma_{T L}^{2}$ \\
\hline$T * L$ & $o^{2}$ & & & & $+1,14$ & $\sigma_{T L}^{2}$ \\
\hline Residuo & $\sigma^{2}$ & & & & & \\
\hline
\end{tabular}

Tabela 16. Eeperancas dos Quadrados Médios para a Soma de Quadrados Tipo II.

\begin{tabular}{|c|c|c|c|c|c|c|c|}
\hline $\mathrm{CV}$ & & & $E$ & {$[Q M]$} & & & \\
\hline $\mathrm{L}$ & $\sigma^{2}$ & $+10,00$ & $\sigma_{L}^{2}$ & & $+5,00 \alpha_{B}^{2}$ & $+1,40$ & $\sigma_{T L}^{2}$ \\
\hline $\mathrm{T}$ & $\alpha^{2}$ & & & $+Q(t)$ & & $+1,14$ & $\sigma_{T L}^{2}$ \\
\hline$B(L)$ & $\sigma^{2}$ & & & & $+2,00 \sigma^{2}$ & & \\
\hline$T * L$ & $\infty^{2}$ & & & & & $+1,14$ & $\sigma_{\mathrm{TL}}^{2}$ \\
\hline Reoiduo & $\sigma^{2}$ & & & & & & \\
\hline
\end{tabular}


Tabela 17. Esperancae dos Quadrados Médios para a Soma de Quadrados Tipo III.

\begin{tabular}{|c|c|c|c|c|c|c|c|}
\hline CV & & & $\mathrm{E}$ & {$[Q M]$} & & & \\
\hline$L$ & $\sigma^{2}+$ & 9,14 & $\sigma_{L}^{2}$ & & $+4,57 \sigma_{B}^{2}$ & $+1,14$ & $\sigma_{T L}^{2}$ \\
\hline$T$ & $\sigma^{2}$ & & & $+Q(t)$ & & $+1,14$ & $\sigma_{T L}^{2}$ \\
\hline$B(L)$ & $\sigma^{2}$ & & & & $+2,00 \sigma_{B}^{2}$ & & \\
\hline$T * L$ & $\sigma^{2}$ & & & & & $+1,14$ & $\sigma_{T L}^{2}$ \\
\hline Residuo & $\sigma^{2}$ & & & & & & \\
\hline
\end{tabular}

A matriz núcleo da forma quadratica do efeito de tratamento é a mesma para os quatro tipos de soma de quadrados; é apresentada a seguir:

$\left[\begin{array}{rrrrrrrr}3,2 & -0,8 & -0,4 & -0,4 & -0,4 & -0,4 & -0,4 & -0,4 \\ -0,8 & 3,2 & -0,4 & -0,4 & -0,4 & -0,4 & -0,4 & -0,4 \\ -0,4 & -0,4 & 1,6 & -0,4 & -0,4 & 0 & 0 & 0 \\ -0,4 & -0,4 & -0,4 & 1,6 & -0,4 & 0 & 0 & 0 \\ -0,4 & -0,4 & -0,4 & -0,4 & 1,6 & 0 & 0 & 0 \\ -0,4 & -0,4 & 0 & 0 & 0 & 1,6 & -0,4 & -0,4 \\ -0,4 & -0,4 & 0 & 0 & 0 & -0,4 & 1,6 & -0,4 \\ -0,4 & -0,4 & 0 & 0 & 0 & -0,4 & -0,4 & 1,6\end{array}\right]$

A Esperanca do Quadrado Médio Tipo IV, neste caso, é a mesma que a encontrada para o Tipo III. Fazendo-se uma análise geral das esperancas, verifica-se que nem sempre o quadrado médio do residuo o melhor testador para os demais efeitos. 
Uma maneira para determinar o quadrado médio apropriado, para o teste dos efeitos do modelo, pode ser através da opção TEST, acrescentada após o comendo RANDOM ne FROC GLM do SAS (1987). O procedimento que o pacote computacional SAS (1987) usa nesta opç̃o é o seguinte:

a. Primeiramente é construida uma matriz dos coeficientes das $\mathrm{E}[\mathrm{QM}]$ dos efeitos que foram considerados aleatorios.

b. Em seguida, para cada efeito do modelo é determinada uma combinação das $\mathrm{E}$ [QM] que irão formar uma esperança contendo todos os termos da $\mathrm{E}$ [QM] do efeito de interesse, com exceça daquele correspondente ao efeito de interesse.

c. Quando for necessario combinar mais de um quadrado médio, deve-se ajustar os graus de liberdade, através do método desenvolvido por SATTERTHWAITE (1941, 1946). Existindo mais de um efeito fixo no modelo, os testes de hipoteses envolvendo um efeito fixo de interesse somente serão válidos se os demais forem assumidos como sendo zero. Neste casóe impressa uma nota lembrando que essas pressuposiç̃̃ee são necessarias para validar o teste. Apesar dos testes não serem válidos, a menos que algumas pressuposiç̃es sejam feitas, isto não propicia uma base para que sejam verdadeiras.

Para compor o denominador apropriado para o teste de cada efeito do modelo, em cada tipo de soma de quadrados, no exemblo ilustrativo, fol utilizada s opsão TEST, gerando as informações apresentadas nas tabelas 18,19 e 20. 
Uma vez que, no exemplo estudado não existem diferencas entre as Somas de Quadrados Tipo III e IV, os testes de hipóteses são idénticos. Deve-se ressaltar que o exemplo aqui adotado teve como intuito apenas ilustrar a metodologia usada. 
Tabela 18. Testes de hipóteses para somas de quadrados Tipo I

CV : Local

Erro: 1,4286 QM B(L) + 0,85 QM T*L - 1,2786 QM Res

GL do numerador: 1

SQ do numerador: 10035,20

GL do denominador: 4,31

$S Q$ do denominador: 382,7443

F calculado: 26,219

CV: Tratamento

Erro: 0,1224 QM B(L) + 1,0429 QM T*L - 0,1653 QM Res

GL do numerador: 7

SQ do numerador: 99,2214

GL do denominador: 8,15

SQ do denominador: 204,3027

F calculado: 0,486

CV: $B 1000$ (Local)

Erro: 0,2625 QM T*L + 0,7375 QM Res

GL do numerador: 2

SQ do numerador: 173,1625

GL do denominador: 8,81

SQ do denominador: 55,535

F calculado: 3,118

CV: Local * Tratamento

Erro: QM Res

GL do numerador: 7

SQ do numerador: 177,4964

GL do denominador: 2

SQ do denominador: 12,125

F calculado: 14,639 
Tabela 19. Testes de hipóteses para somas de quadrados Tipo II

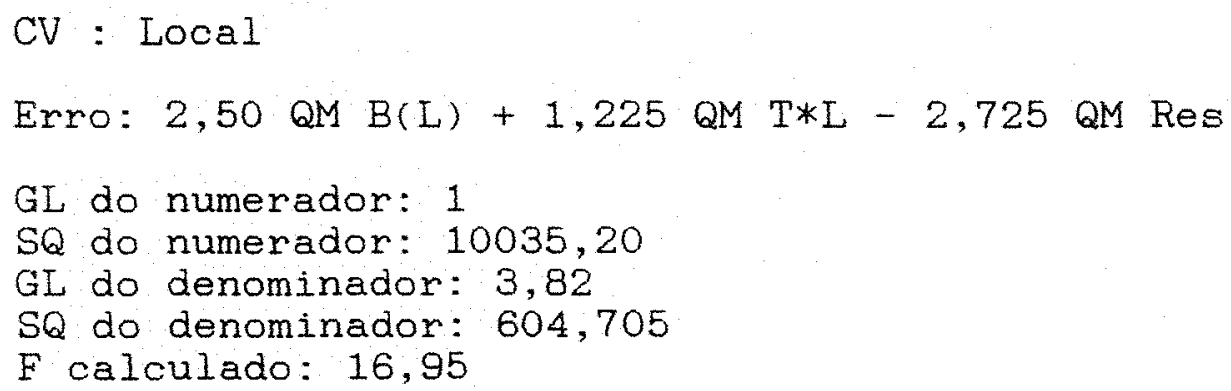

CV: Tratamento

Erro: QM T*L

GL do numerador: 7

SQ do numerador: 132,2393

GL do denominador: 7

SQ do denominador: 177,4964

F calculado: 0,75

\section{CV: Bloco(Local)}

Erro: QM Res

GL do numerador: 2

$S Q$ do numerador: 168,125

GL do denominador: 2

$S Q$ do denominador: 12,125

E calculado: 13,66

CV: Local * Tratamento

Erro: QM Res

GL do numerador: 7

SQ do numerador: 177,4964

GL do denominador: 2

SQ do denominador: 12,125

$F$ calculado: 14,39 
Tabela 20. Testes de hipoteses para somas de quadrados Tipo III

CV : Local

Erro: 2,2857 QM B(L) + QM T*I - 2,2857 QM Res

GL do numerador: 1

SQ do numerador: 10560,02

GL do denominador: 3,62

$\mathrm{SQ}$ do denominador: 534,068

F calculado: 19,773

CV: Tratamento

Erro: QM T*L

GL do numerador: 7

$S Q$ do numerador: 132,2393

GL do denominador: 7

$S Q$ do denominador: 177,4964

$F$ calculado: 0,745

CV: Bloco(Local)

Erro: QM Res

GL do numerador: 2

$S Q$ do numerador: 168,125

GL do denominador: 2

$S Q$ do denominador: 12,125

$F$ calculado: 13,866

CV: Local * Tratamento

Erro: QM Res

GL do numerador: 7

$S Q$ do numerador: 177,4964

GL do denominador: 2

SQ do denominador: 12,125

$F$ calculado: 14,639 


\section{MATERIAL E METODOS}

Para o desenvolvimento do presente trabalho, foram utilizados os dados de produção de cana-de açúcar, em t/ha de cinco experimentos, instalados segundo o delineamento em blocos completos aumentados, analisados por NOGUEIRA (1976).

Cada experimento foi composto por 4 blocos e por $t=c+z=c+\sum_{j} p_{j}$ tratamentos, sendo:

(i) $c=3$ cultivares, considerados como os tratamentos comuns presentes nos 4 blocos;

(ii) $\mathrm{p}_{j}=3$ cultivares, considerados como os tratamentos regulares presentes no blocoj, $\operatorname{com} j=1,2,3,4$;

$$
\text { (iii) } t=3+4 \times 3=3+12=15 \text { cultivares de cana-de-a- }
$$
çucar, no total;

Deve-se ressaltar que cada bloco foi composto por $\mathrm{n}=\mathrm{c}+\mathrm{p}_{\mathrm{j}}$ parcelas.

Os tratamentos comuns foram identificados por A, B e $C$ e os regulares por $a, b, c, d, e, f, g, h, i, j, k, 1$. Assim, pode-se exemplificar a composiça de cada bloco de um dos experimentos da seguinte forma: 


\begin{tabular}{|c|c|c|c|}
\hline bloco 1 & b 10002 & bloco3 & bloco 4 \\
\hline A & 1 & $j$ & $B$ \\
\hline h & $b$ & $\mathrm{C}$ & $\mathrm{C}$ \\
\hline$C$ & $B$ & $B$ & A \\
\hline$B$ & C & $e$ & $k$ \\
\hline$B$ & 1 & $\mathrm{~g}$ & $a$ \\
\hline$c$ & $A$ & $A$ & $f$ \\
\hline
\end{tabular}

Os dados obtidos neste grupo de experimentos encon tram-se na Tabela 21.

A anallse desses dados fol efetuada em duas etapas, a saber:

a.) Análise individual para cada local ou experimento;

b.) Análise conjunta, incluindo os resultados obtidos em todos os experimentos. 
Tabela 21. Dados de producão de cane de acúcar em t/he.

Loc. Blocos Produça $(t / h a)$

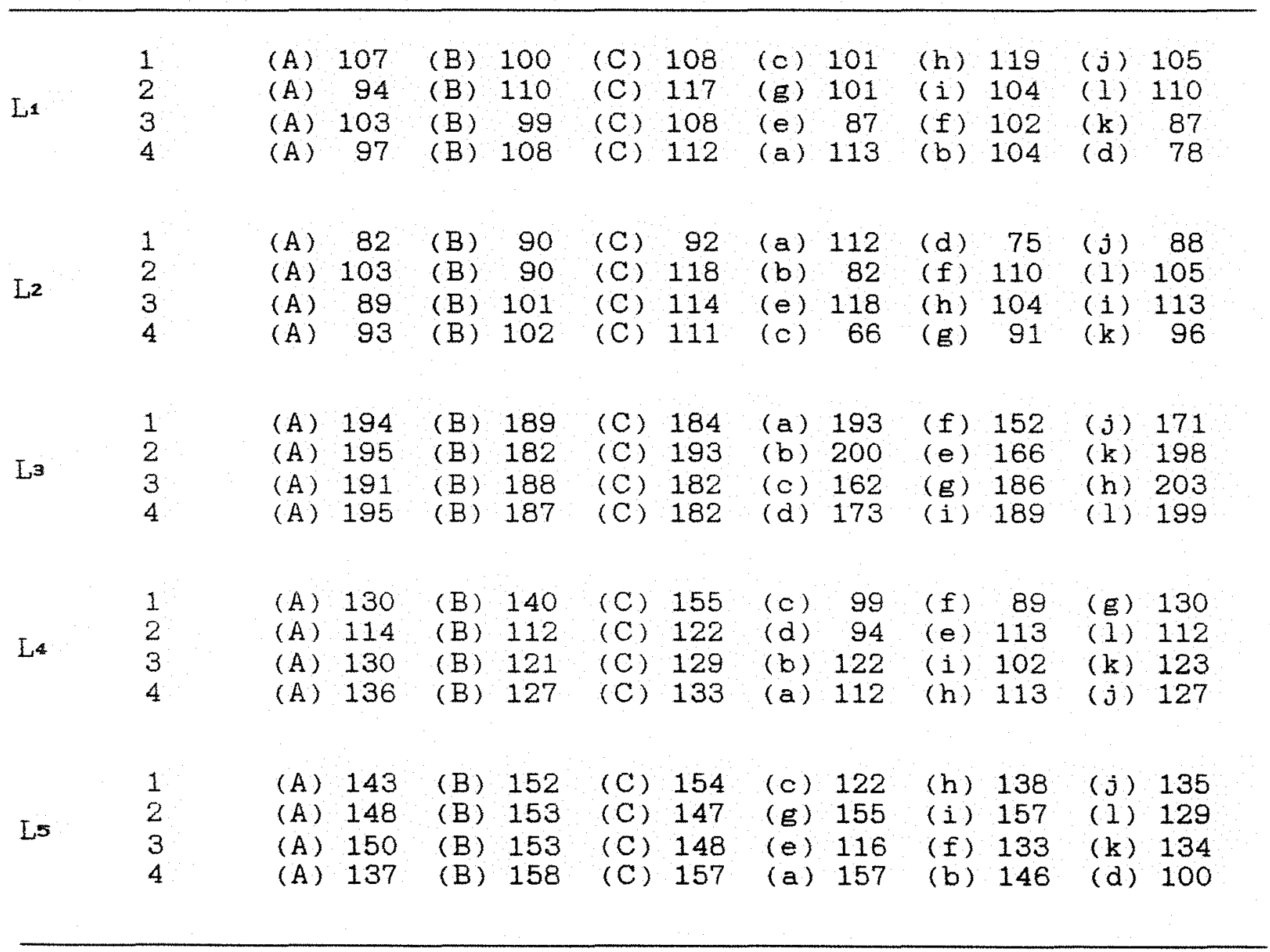




\subsection{Análise Individual}

A análige individual teve por objetivo obter infor mações referentes a cada um dos experimentos ou locals. Uma vez que a análise conjunta oomente pode ser efetuada se houver homogeneidade de variáncies entre os quadrados médios residuais doe expe rimentos, a análise individual deve ser o ponto de partida deste estudo.

A homogeneldade de variancias pode ser verificada atraves de testes citados na literatura, sendo que 0 teste $F_{\max }$, tambem conhecido por teste de Hartley, o comumente usado.

Uma regra prática descrita por alguns autores, den tre eles PIMENTEL GOMES (1978), para que possa ser verificada a homogeneidade de variáncias, consiste em determinar a razão entre o maior e o menor quadrado médio residual. Se essa relação ultrapasear a proporção $4: 1$, pode hever indício de heterocedesticie.

Se a heterogeneidade de variancias for detectada, segundo COCHRAN (1954), pode-se resolver o problema de duas maneiras:

a.) Separar os experimentos em sub-grupos homocedásticos e analisá-los separadamente;

b.) Ajustar oe graus de liberdade do resi duo médio e os da interaça entre local e tratamento.

Para a análige individual fol adotado o seguinte modelo matemático: 


$$
y_{i j}=\mu+\alpha_{i}+\beta_{j}+\varepsilon_{i j}
$$

com, $i=1,2, \ldots, 15$ e $j=1,2, \ldots, 4$

onde,

$y_{i j}$ e valor obeervado referente do i-esimo tratamento no j-esi mo bloco;

$H$ é uma constante inerente e todas as observaços:

$\alpha_{i} \quad$ e o efeito do i-esimo tratamento;

$\beta_{j} \quad$ é efeito do j-éeimo bloco;

$\varepsilon_{i j}$ é erro experimental assoclado a $y_{i j}$, tal que $\varepsilon_{i j} \sim \mathbb{N}\left(0, \sigma^{2}\right)$.

Para o estudo das funç̧es estimáveis e das esperan cas do quadrado médio de cada efeito do modelo, fol utilizada a metodologia descrita durante a exposição do DESENVOLVIMENTO TEORICo (Capl tulo 3$)$.

\subsection{Analise Conjunta}

Uma vez constatade a homogeneidade de variáncias entre os experimentos, fol possi vel reuni-los em uma análise conjunta para que se poesa obter informaços de ordem geral.

O modelo matemático adotado neste caso, passou a ser:

$$
y_{i j k}=\mu+\lambda_{k}+\alpha_{i}+\beta_{j \mid k}+\gamma_{k i}+\varepsilon_{i j k}
$$


com $i=1,2, \ldots, 15 ; j=1,2, \ldots, 4$ e $k=1,2, \ldots, 5$, onde:

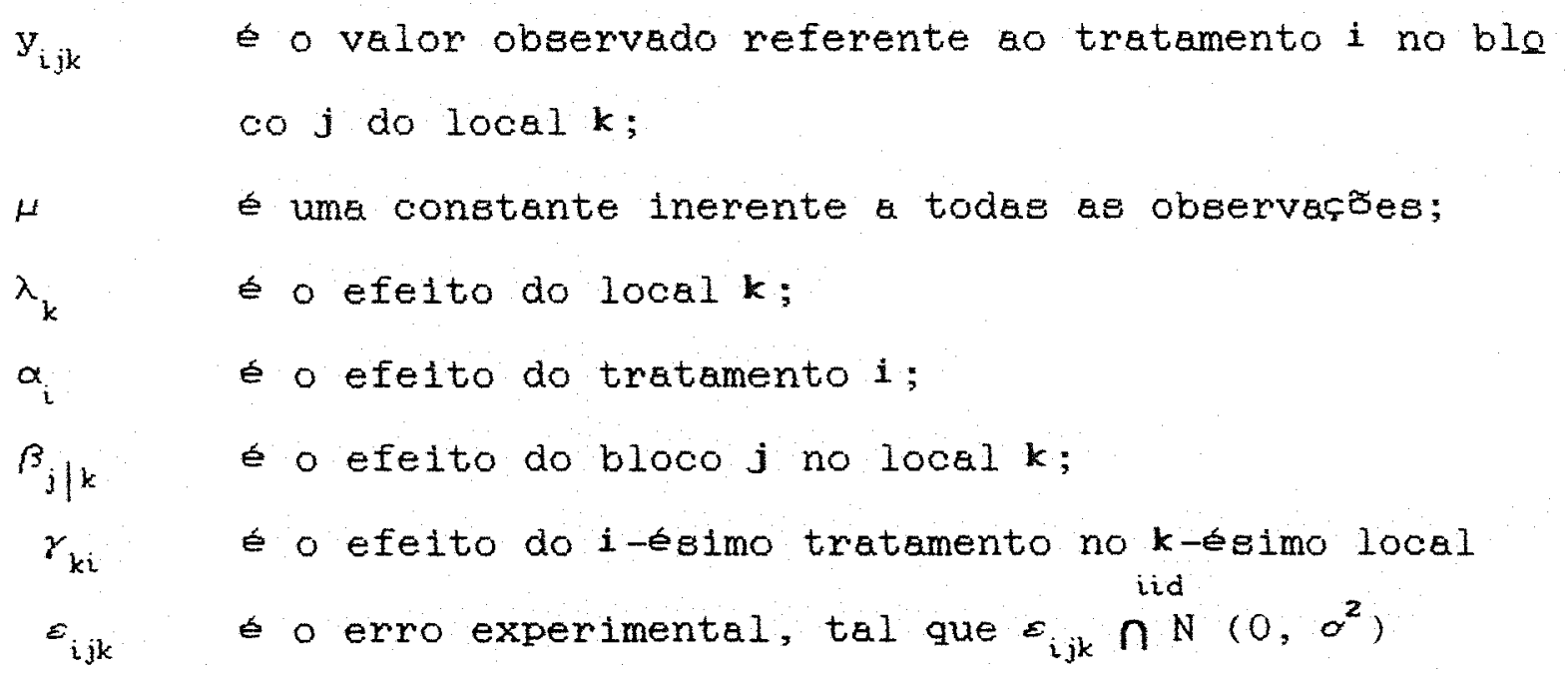

Deve-se ressaltar que o modelo adotado no presente trabelho e um modelo misto, onde o fator tratamento foi conslderado como efeito fixo, enquanto que o fator bloco foi considerado aleatório.

Essa ansise fol efetuada utilizando a metodologia descrita no Capi tulo 3 , a fim de se verificar, entre as quatro somas de quadrados, qual delas foi a mais adequada para o delineamento proposto neste estudo. 


\section{RESULTADOS E DISCUSSAO}

\subsection{Análise individual}

Observando-se a Tabela 21 , verifica-se que todos os experimentos são compostos pela mesma estrutura. Dessa maneira, a forma geral das funçóes estimáveis é a mesma para os cinco experimentos estudados, conforme mostra a Tabela 22.

Seguindo-se a metodologia descrita no capitulo 3 , obtiveram-se as funcoses estimaveis Tipo I, II, III e IV, a fim de que o pesquisador possa verificar quais hipoteses serão testadas em cada soma de quadrados fornecida pelo SAS (1987).

Assim, as hipóteses testadas para as somas de quadrados Tipo I, II, II e IV foram calculadas e verificou-se que as do Tipo II, III e IV năo diferiram entre si. Os resultados obtidos são apresentados nas Tabelas 23 e 24 , para o Tipo I e Tipos II, III e IV, respectivamente. 
Tabela 22. Forma geral das funçases estimáveis para o modelo

$$
y_{i j}=\mu+\alpha_{i}+\beta_{j}+\varepsilon_{i j}
$$

\begin{tabular}{|c|c|}
\hline Parâmetros & Coeficientes \\
\hline$\mu$ & Lx \\
\hline$\alpha i$ & $\mathrm{I}_{2}$ \\
\hline$\alpha z$ & La \\
\hline$\alpha$ & IA \\
\hline$\alpha 4$ & Ls \\
\hline$\alpha s$ & Lo \\
\hline$\alpha ?$ & La \\
\hline$\alpha \theta$ & Lo \\
\hline$\infty$ & L,o \\
\hline a1o & L11 \\
\hline a11 & Laz \\
\hline$\alpha_{12}$ & L19 \\
\hline$\alpha_{13}$ & Ls4 \\
\hline ar: & LAs \\
\hline$\alpha \times 5$ & $I_{1}-I_{2}-I_{3}-I_{4}-I_{s}-L_{0}-I_{2}-I_{0}-I_{0}-I_{10}-I_{11}-L_{12}-I_{19}-I_{14}-I_{15}$ \\
\hline$\beta_{1}$ & Li? \\
\hline$\beta 2$ & Las \\
\hline$\beta 3$ & Leso \\
\hline$\beta_{4}$ & $L_{1}-I_{17}-I_{18}-I_{10}$ \\
\hline
\end{tabular}


Tabela 23. Hipóteses testadas através da Soma de Quadrados Tipo I

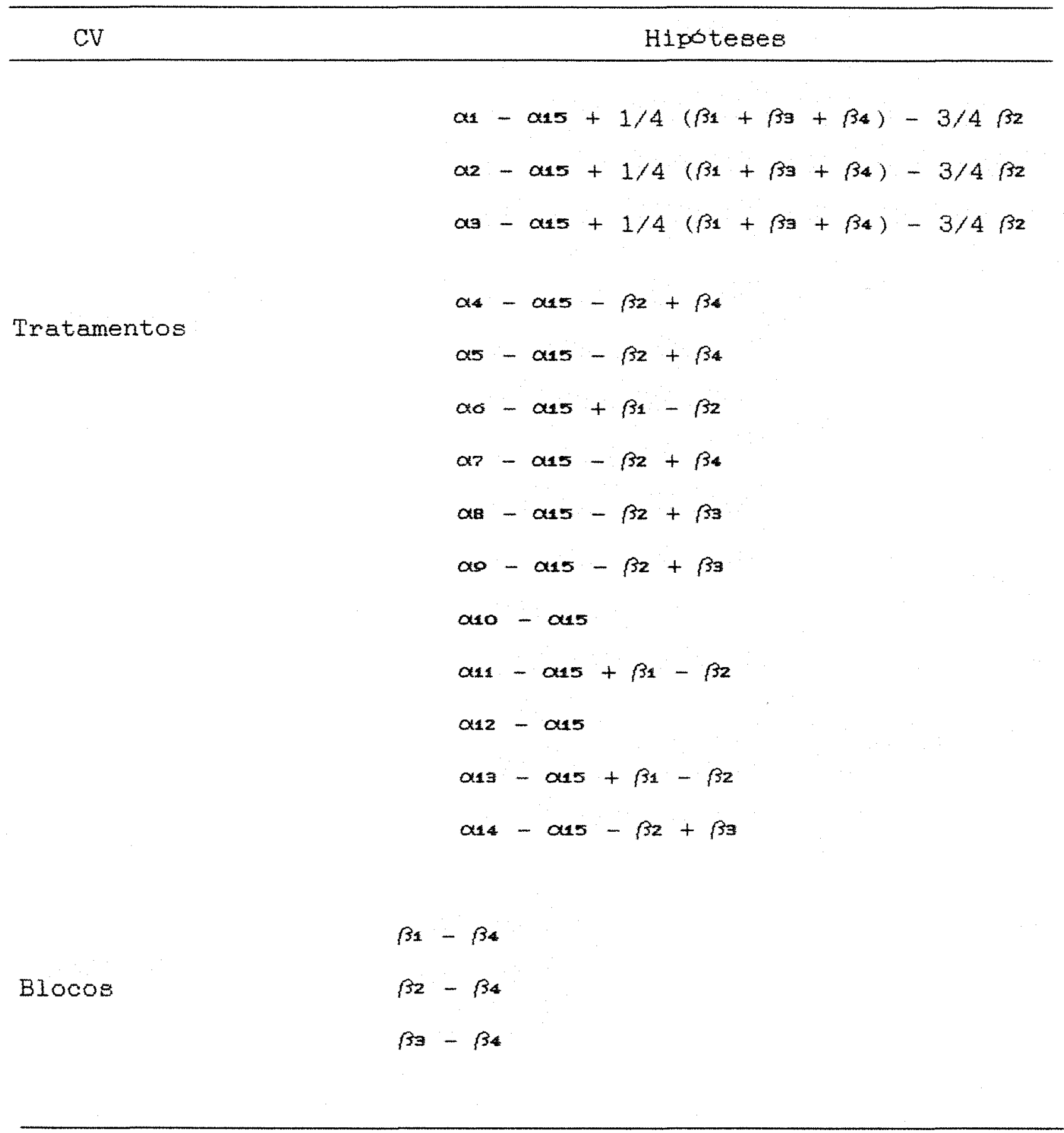


Tabela 24. Hipóteses testadas atraves das Somas de Quadrados Tipos II, III e IV.

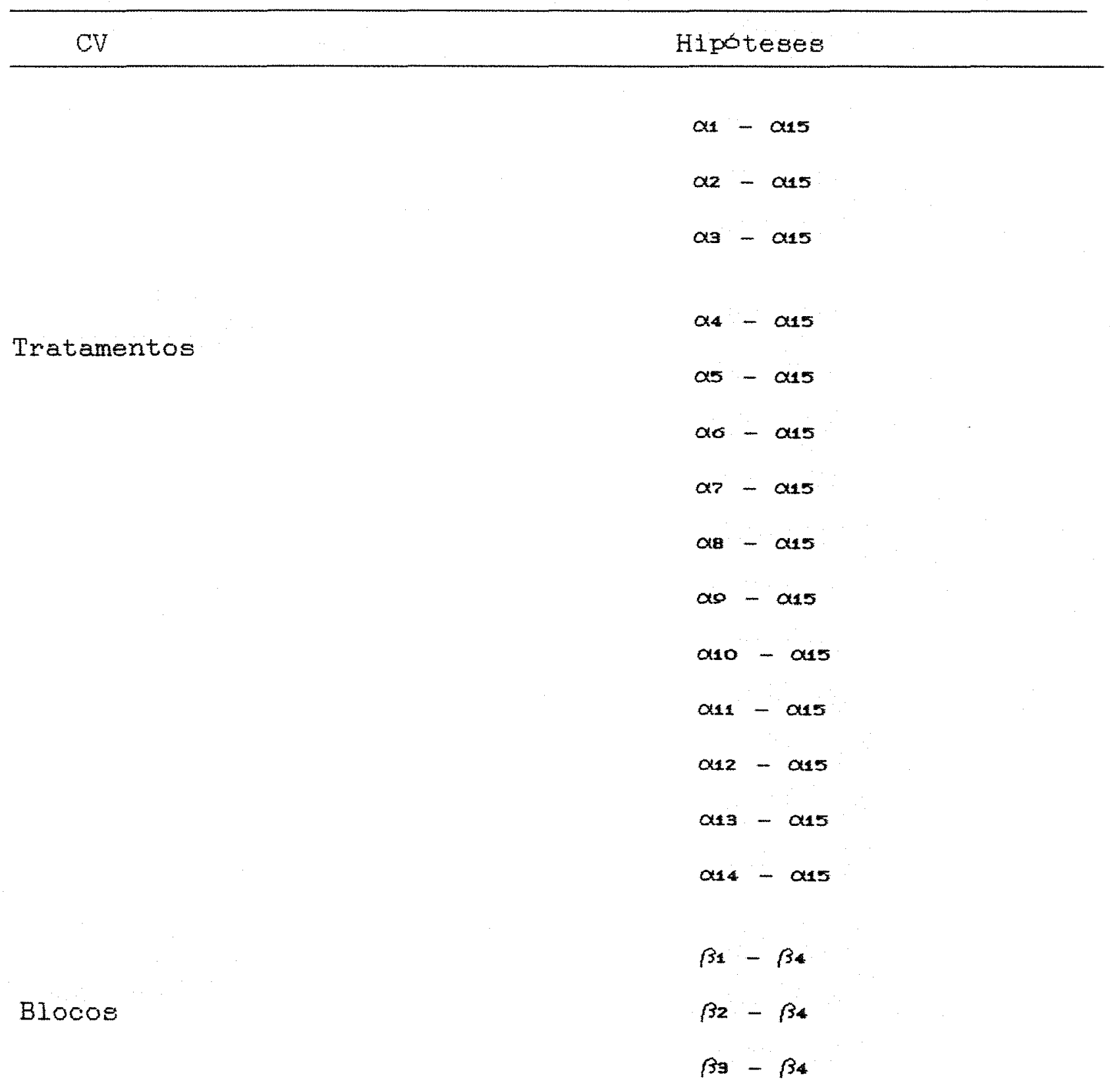


A Tabela 23 indica que a hipotese Tipo I, testada para o fator tratamento contem, além do efeito de interesse, o efeito do fator bloco; portanto, a soma de quadrados Tipo I para o modelo em questão, não testa apenas a hipotese $H_{0}: a_{i}=0$. Como foi verificado no Capi tulo 3 , uma inversão na ordem de entrada dos fatores do modelo, modifica a soma de quadrados e também as hipóteses testadas. A Tabela 24 indica que as hipoteses Tipos II, III ou IV testam apenas o efeito de tratamento, sem a interferencia do efeito de blocos.

Para poder compor um quadrado medio apropriado aos testes de hipoteses de interesse, foram calculadas as Esperancas dos Quadrados Médios, E [OM], pare os quatro tipos de somas de que drados. Como as hipóteses Tipo II, III e IV são as mesmas, consequentemente as $E$ [QM] não variam. As Tabelas $25 a$ e e $25 b$. , a seguir contem as $E$ [QM] para as hipoteses Tipo I e II, III ou IV. 
Tabela 25a. Esperanças dos Quadrados Médios para a Some de Quadre dos Tipo I, em cada Local ou Experimento.

\begin{tabular}{|c|c|}
\hline $\mathrm{CV}$ & $E[Q M]$ \\
\hline Tratamentos & $\sigma^{2}+Q(t)+0,6429 \sigma_{\mathrm{B}}^{2}$ \\
\hline Blocos & $\sigma^{2} \quad+3,0 \sigma^{2}$ \\
\hline Resi duo & $\sigma^{2}$ \\
\hline
\end{tabular}

Tabela 25b. Esperanças dos Quadrados Médios para a Soma de Quadra dos Tipos II, III e IV, em cada Local ou Experimento.

\begin{tabular}{ll}
\hline CV & $E[Q M]$ \\
\hline Tratamentos & $\sigma^{2}+Q(t)$ \\
Blocos & $\sigma^{2}+3,0 \sigma^{2}$ \\
Residuo & $\sigma^{2}$ \\
\hline
\end{tabular}


Analisando-se a Tabela 25a., verifica-se que para a soma de quadrados Tipo I, a esperanca do quadrado médio para o fator tratamento contém, além do efeito de interesse, a adič̃o do efeito de bloco. Assim, na obtenfã da estatistica F para o efel to de tratamento é necessario compor o quadrado medio do denominedor e, consequentemente, ajustar os seus graus de liberdade.

Para as somas de quadrados Tipos II, III e IV, a estati stica $\mathrm{E}$ para o efeito de tratamento, pode ser obtida atraves do quadrado medio do regi duo para o denominador, uma vez que a E [QM] para o efeito de interesse inclui apenas o componente do $e-$ feito de tratamento mais a variancia do erro.

Como padrão (default) o pacote computacional SAS (1987), coneidera o denominador da estatistica $\mathrm{E}$ sempre com o quadrado médio do resíduo, nos quatro tipos de somas de quadrados. Desea forma, deve-se estar consciente de que a estatistica $F$ para - efeito de tratamento, na soma de quadrados Tipo I, não testa ape nas o efeito de intereese; eeta adicionado o efeito de blocos.

As análises de varianclas obtidas para os cinco 10 cais encontram-se nas Tabelas 26a., 26b., 27a, 27b., 28a., 28b., 29a., 29b., 30a., e 30b...Verifica-se que as somas de quadrados Tipos II, III e IV são lguals e diferem da soma de quadrados Tipo I. 
Tabela 26a. Análise de variância apresentando as somas de quadra dos Tipo I, para o Local ou Experimento 1.

\begin{tabular}{lrrrrr}
\hline \multicolumn{1}{c}{ CV } & GL & SQ & QM & F & Pr $>F$ \\
Tratamentos & 14 & 1861,08 & 132,93 & 3,48 & 0,0668 \\
Blocos & 3 & 20,92 & 6,97 & 0,18 & 0,9046 \\
Resi duo & 6 & 229,33 & 38,22 & & \\
\hline Total & 23 & 2111,33 & & & \\
\hline
\end{tabular}

Tabela 26b. Análise de variâncla apresentando as somas de quadra dos Tipo II, III e IV, para o Local ou Experimento 1.

\begin{tabular}{lrrrrr}
\hline CV & GL & SQ & QM & F & Pr $>F$ \\
\hline Tratamentos & 14 & 1558,67 & 111,33 & 2,91 & 0,0977 \\
Blocos & 3 & 20,92 & 6,97 & 0,18 & 0,9046 \\
Residuo & 6 & 229,33 & 38,22 & & \\
\hline Total & 23 & 2111,33 & & & \\
\hline
\end{tabular}


Tabela 27a. Análise de variancia apresentando as somas de quadra dos Tipo I, para o Local ou Experimento 2.

\begin{tabular}{lccccc}
\hline CV & GL & SQ & QM & F & Pr $>F$ \\
Tratamentos & 14 & 3648,71 & 260,62 & 5,37 & 0,0242 \\
Blocos & 3 & 470,92 & 156,97 & 3,23 & 0,1030 \\
Residuo & 6 & 291,33 & 48,56 & & \\
\hline Total & 23 & 4410,96 & & & \\
\hline
\end{tabular}

Tabela 27b. Análise de variância apresentando as somas de quadre dos Tipo II, III e IV, para o Local ou Experimento 2.

\begin{tabular}{lccccc}
\hline CV & GL & SQ & QM & F & Pr $>F$ \\
\hline Tratamentos & 14 & 3081,17 & 220,08 & 4,53 & 0,0364 \\
Blocos & 3 & 470,92 & 156,97 & 3,23 & 0,1030 \\
Regi duo & 6 & 291,33 & 48,56 & & \\
\hline Total & 23 & 4410,96 & & & \\
\hline
\end{tabular}


Tabela 28a. Análise de variancia apresentando as bomas de quadra dos Tipo I, para o Local ou Experimento 3.

\begin{tabular}{lrrrrr}
\hline CV & GL & SQ & QM & F & Pr $>F$ \\
\hline Tratamentos & 14 & 3621,33 & 258,67 & 14,44 & 0,0018 \\
Blocos & 3 & 15,00 & 5,00 & 0,28 & 0,8389 \\
Regiduo & 6 & 107,50 & 17,92 & & \\
\hline Total & 23 & 3743,83 & & & \\
\hline
\end{tabular}

Tabela zob. Análise de variancia apresentando as somas de quadrs dos Tipo II, III e IV, para o Local ou Experimento 3.

\begin{tabular}{lrrrrr}
\hline CV & GL & SQ & QM & F & Pr $>F$ \\
\hline Tratamentos & 14 & 3388,83 & 242,06 & 13,51 & 0,0021 \\
Blocos & 3 & 15,00 & 5,00 & 0,28 & 0,8389 \\
Residuo & 6 & 107,50 & 17,92 & & \\
\hline Total & 23 & 3743,83 & & & \\
\hline
\end{tabular}


Tabela 29a. Analise de variáncia apresentando as somas de quadra dos Tipo I, para o Local ou Experimento 4.

\begin{tabular}{lccccc}
\hline CV & GL & SQ & QM & F & Pr $>F$ \\
\hline Tratamentos & 14 & 3984,21 & 284,59 & 6,61 & 0,0143 \\
Blocos & 3 & 1031,58 & 343,86 & 7,99 & 0,0162 \\
Regi duo & 6 & 258,17 & 43,03 & & \\
\hline Total & 23 & 5273,96 & & & \\
\hline
\end{tabular}

Tabela 29b. Análise de variancia apresentando as somas de quadra dos Tipo II, III e IV, para o Local ou Experimento 4.

\begin{tabular}{lccccc}
\hline CV & GL & SQ & QM & F & Pr $>F$ \\
\hline Tratamentos & 14 & 4321,67 & 308,69 & 7,17 & 0,0116 \\
Blocos & 3 & 1031,58 & 343,86 & 7,99 & 0,0162 \\
Residuo & 6 & 258,17 & 43,03 & & \\
\hline Total & 23 & 5273,96 & & & \\
\hline
\end{tabular}


Tabela 30a. Análise de variâncla apresentando as somas de quadra dos Tipo I, para o Local ou Experimento 5.

\begin{tabular}{lrrrrr}
\hline CV & GL & SQ & QM & $F$ & Pr $>F$ \\
\hline Tratamentos & 14 & 4807,83 & 343,42 & 10,92 & 0,0038 \\
Blocos & 3 & 3,33 & 1,11 & 0,04 & 0,9902 \\
Regiduo & 6 & 188,67 & 31,44 & & \\
\hline Total & 23 & 4999,83 & & & \\
\hline
\end{tabular}

Tabela 3ob. Analise de variancia apresentando as somas de quadra dos Tipo II, III e IV, para o Local ou Experimento 5.

\begin{tabular}{lrrrrr}
\hline CV & GL & SQ & QM & E & Pr $>F$ \\
\hline Tratamentos & 14 & 4525,00 & 323,21 & 10,28 & 0,0045 \\
Blocos & 3 & 3,33 & 1,11 & 0,04 & 0,9902 \\
Residuo & 6 & 188,67 & 31,44 & & \\
\hline Total & 23 & 4999,83 & & & \\
\hline
\end{tabular}


Como fol citado no Capi tulo 3 , a opcão TEST na PROC GLM do SAS (1987) estima o quadrado médio apropriado para testar oe efeitos do modelo, quando se torna necesbário fazer ume composi çăo do quadrado médio do denominador. No caso do presente estudo apenas o fator tratamento, na soma de quadrados Tipo I, necessita desse ajuste, como se observa na Tabela 25 a. Dessa forma, os resul tados obtidos através da op̧̃̃o TEST do comando RANDOM para os locais 1 e 2 , encontram-se na Tabela 31 e, para os locais 3,4 e 5 , na Tabela 32 .

Tabela 31. Resultados obtidos atraves da opsão TEST na PROC GLM do SAS para os Locais 1 e 2 .

Local 1

CV: Tratamento

Erro: 0,2143 QM BI + 0,7857 QM Res

GL do denominador: 6,58

SQ do denominador: 31,52

F calculado: 4,22

$\operatorname{Pr}>\mathrm{F}: 0,0359$

Local 2

CV: Tratamento

Erro: $0,2143 \mathrm{QM} \mathrm{BI}+0,7857 \mathrm{QM}$ Res

GL do denominador: 8,32

$\mathrm{SQ}$ do denominador: 71,79

$F$ calculado: 3,63

$\mathrm{Pr}>\mathrm{E}: 0,0337$ 
Tabela 32. Resultados obtidos atraves da opcão TEST na PROC GLM do SAS para os Locais 3,4 e 5 .

Local 3

CV: Tratamento

Erro: $0,2143 \mathrm{QM} \mathrm{BI}+0,7857 \mathrm{QM}$ Res

GL do denominador: 6,87

$S Q$ do denominador: 15,15

F calculado: 17,075

Pr > F: 0,0005

Local 4

CV: Tratamento

Erro: $0,2143 \mathrm{QM} \mathrm{BI}+0,7857 \mathrm{QM}$ Res

GL do denominador: 5,78

SQ do denominador: 107,49

$F$ calculado: 2,648

$\operatorname{Pr}>\mathrm{F}: 0,1239$

Local 5

CV: Tratamento

Erro: 0,2143 QM BI + 0,7857 QM Res

GL do denominador: 6,12

$S Q$ do denominador: 24,94

F calculado: 13,767

Pr > F : 0,0018 
Aplicando-se o Teste de Hartley para testar a hipótese referente a homocedasticidade, verifica-se que $H_{0}$ não é rejei tada, ao nível de 0,05 de significância, isto é:

$$
\frac{\mathrm{QM}^{\operatorname{Res}_{(k)}\{\max \}}}{\mathrm{QM} \operatorname{Res}_{(k)}\{\min \}}=\frac{48,56}{17,92}=2,71
$$

De acordo com a tabela de Hartley, encontrada em PEARSON \& HARTLEY (1956), verifica-se que o valor crítico para $\alpha=0.05$, con $n_{1}=6$ (graus de liberdade associados aos quadrados médios dos resíduos) e $n_{2}$ (números de variancias envolvidas) é igual a 12,10 .

\section{2. Analise Conjunta}

Para a ańlise conjunta do grupo de experimentos em blocos completos aumentados, seguiu-se a mesma metodologia descrita no Capi tulo 3.

De uma maneira geral, quando se trabalha com grupo de experimentos, a quantidade de variáveis resposta é muito grande, dificultando a transcrição das hipóteses testadas para cada tipo de soma de quadrados fornecida pelo SAS (1987). Uma outra maneira de se verificarem as hipoteses testadas, nestas somas de quadrados, é através da esperanca do quadrado médio.

Considerando o fator tratamento como efeito fixo e os demais, como aleatorios, os resultados obtidos através do comando RANDOM na PROC GLM do SAS encontram-se nas Tabelas 33,34 e 35 , para as Somas de Quadrados Tipos I, II e III, respectivamente. 
Não sera incluida a E [QM] Tipo IV pois esta não diferiu do Tipo III.

Tabela 33. Esperanças dos Quadrados Médios para a Soma de Quadra dos Tipo I.

\begin{tabular}{|c|c|c|c|c|}
\hline $\mathrm{CV}$ & & $E[Q M]$ & & \\
\hline L & $\sigma^{2}+24 \sigma_{L}^{2}$ & & $+6,00 \sigma^{2}$ & $+2,5 \sigma_{\mathrm{TL}}^{2}$ \\
\hline$T$ & $\sigma^{2}$ & $+Q(t)$ & $+0,64 \sigma^{2}$ & $+1,54 \sigma_{\mathrm{TL}}^{2}$ \\
\hline$B(L)$ & $o^{2}$ & & $+5,40 \sigma^{2}$ & $+0,43 \sigma_{\mathrm{TL}}^{2}$ \\
\hline $\mathrm{T} * \mathrm{~L}$ & $\alpha^{2}$ & & & $+1,42 \sigma_{\mathrm{TL}}^{2}$ \\
\hline Resi duo & $\sigma^{2}$ & & & \\
\hline
\end{tabular}

Tabela 34. Esperanças dos Quadrados Médios para a Soma de Quadre dos Tipo II.

\begin{tabular}{|c|c|c|c|c|}
\hline $\mathrm{CV}$ & & $E[Q M]$ & & \\
\hline L & $\sigma^{2}+24 \sigma_{L}^{2}$ & & $+6,00 \sigma_{B}^{2}$ & $+2,5 \sigma_{\mathrm{TL}}^{2}$ \\
\hline $\mathrm{T}$ & $\sigma^{2}$ & $+Q(t)$ & & $+1,46 \sigma_{\mathrm{TL}}^{2}$ \\
\hline$B(L)$ & $\sigma^{2}$ & & $+3,00 \sigma^{2}$ & \\
\hline$T * L$ & $\sigma^{2}$ & & & $+1,42 \sigma_{\mathrm{TL}}^{2}$ \\
\hline Resi duo & $\sigma^{2}$ & & & \\
\hline
\end{tabular}


Tabela 35. Esperanças dos Quadrados Médios para a Soma de Quadra dos Tipo III.

\begin{tabular}{|c|c|c|c|c|}
\hline $\mathrm{CV}$ & & $E[Q M]$ & & \\
\hline L & $\sigma^{2}+17,65$ & $\sigma_{L}^{2}$ & $+4,41 \sigma^{2}$ & $+1,18 \sigma_{\mathrm{TL}}^{2}$ \\
\hline$T$ & $\sigma^{2}$ & $+Q(t)$ & & $+1,39 \alpha^{2}$ \\
\hline$B(L)$ & $\sigma^{2}$ & & $+3,00 \sigma_{B}^{2}$ & \\
\hline$T * L$ & $\alpha^{2}$ & & & $+1,42 \sigma^{2}$ \\
\hline Resi duo & $\sigma^{2}$ & & & \\
\hline
\end{tabular}

Comparando-se os resultados obtidos para as esperancas do presente experimento e as obtidas para o exemplo desenvolvido no Capítulo 3 verifica-se que os componentes de variancia presentes em cade esperanca são os mesmos, variando apenas os coeficientes que antecedem cada uma delas.

Neste caso, observou-se que na $E[Q M]$ referente a Tratamentos e ì interaçăo Local*Tratamento, os coeficientes corres pondentes aos componentes de variancia da interaça inclúlos nela apresentaram uma pequena variaça. Este fato pode estar relacionado com o número de condicão de matriz pois, segundo IEMMA $(1990)^{1}$, matrizes com altos números de condiça podem gerar serios problemas em termos de aproximacões numéricas.

(1) IEMMA, A.F.. Algebra de matrizes com aplicaçóes em estatistica. Piracicaba, ESALQ/USP. Departanento de Matemática e Estati stica. Mimeografado. 390 p., 1990. 
Montgomery \& Peck (1981), citados por FERRARI

(1989), indicam que o número de condiça da matriz pode ser dado por:

$$
K(x)=\frac{\lambda_{\max }}{\lambda_{\operatorname{mim}}}
$$

onde,

$$
\begin{aligned}
& \lambda_{\max } \text { é o maior auto - valor da matriz } \\
& \lambda_{\min } \text { é o menor auto - valor da matriz, }
\end{aligned}
$$

Salienteram tamben que, se o número condiç̃o for menor que 100, não existe problema serio de multicolinearidade. Entre 100 e 1000 impli ca em multicolinearidade de moderada a forte e, se $\mathrm{K}$ ( $\mathrm{x}$ ) for maior que 1000 , indica uma multicolinearidade severa.

A multicolinearidade ocorre em uma análise quando as observaços amostrais das variáveis independentes, ou as combinaçชes lineares entre elas, são altamente correlacionadas.

Para a verificaça deste fato, foram obtidos os als to-valores da forma quadrática para o efeito de tratamento, onde $\lambda_{\text {max }}=20,00$ e $\lambda_{\text {min }}=0,0000147 ;$ portanto:

$$
K(x)=\frac{20,00}{0,0000147}=1360544,218
$$

Dessa forma, verifica-se que existe uma multicolinearidade severa, que provavelmente interferiu na aproximaça dos resultados.

Assim, não existindo multicolinearidade entre os dados, a estatistica F obtida para o efeito de tratamento, nae So- 
mas de Quadrados Típos II e II terá como denominador o quadrado medio da interação $T * L ; 0$ efeito de bloco e a interação T*L terão como denominador o quadrado médio residual; para o efeito de local - denominador devera ser obtido atraves da composição das quadrados médios dos efeitos envolvidos. Na Soma de Quadrados Tipo I, com exceç̃o da interaçă a estatística $F$ para os demais efeitos do modelo terão como denominador uma composição de quadrados medios e, consequentemente, os graus de liberdade associados a esse denominador deverão ser ajustados por SATTERTHWAITE $(1941,1946)$.

Os resultados das análiees de variancia, apresente dos nas Tabelas 36,37 e 38 foram obtidos pela PROC GLM do SAS (1987). Uma vez que este pacote computacional considera o denomina dor da estatistica F como o quadrado medio do resíduo, os valores de $F$ não serão incluidos. Posteriormente serão obtidos atraves da opç̃ TEST.

Tabela 36. Análise de variancia apresentando a Soma de Quadrados Tipo I

\begin{tabular}{lcrc}
\hline CV & GL & SQ & QM \\
\hline L & 4 & 122553,38 & 30638,35 \\
$\mathrm{~T}$ & 14 & 8976,35 & 641,17 \\
$\mathrm{~B}(\mathrm{~L})$ & 15 & 1805,35 & 120,36 \\
$\mathrm{~T} * \mathrm{~L}$ & 56 & 8683,22 & 155,06 \\
Resi duo & 30 & 1075,00 & 35,83 \\
\hline Total & 119 & 143093,30 & \\
\hline
\end{tabular}


Tabela 37. Analise de variancia apresentando a Soma de Quadradoe Tipo II.

\begin{tabular}{lrrr}
\hline CV & GL & SQ & QM \\
\hline L & 4 & 122553,38 & 30638,35 \\
T & 14 & 8192,12 & 585,15 \\
B(L) & 15 & 1541,35 & 102,78 \\
T*L & 56 & 8683,22 & 155,06 \\
Resi duo & 30 & 1075,00 & 35,83 \\
\hline Total & 119 & 143093,30 & \\
\hline
\end{tabular}

Tabela 38. Analise de variancia aprebentando a Soma de Quadrados Tipo III.

\begin{tabular}{lccc}
\hline CV & GL & SQ & QM \\
\hline L & 4 & 88673,45 & 22168,36 \\
T & 14 & 7904,90 & 564,64 \\
B(L) & 15 & 1541,75 & 102,78 \\
T*I & 56 & 8683,22 & 155,06 \\
Resíduo & 30 & 1075,00 & 35,83 \\
Total & 119 & 143093,30 & \\
\hline
\end{tabular}


A fim de compor o quadrado medio apropriado para a estatíf stica $F$ nos quatro tipos de somas de quadrados, fol utilizada a op̧ão TEST do comando RANDOM na PROC GLM do SAS (1987). Os resultados obtidos nas análises de variância, com os graue de liberdade já corrigidos, encontram-se nas Tabelas 39,40 e 41 . 
Tabela 39. Composição da estati stica "F", obtida atravé da opça TEST do comando RANDON para a Soma de Quadrados Tipo I.

Erro: 1,1111 QMB (L) + 1,4217 QMT*L - 1,5328 QMRes

Local GLNun. QMNum. GLDen. QMDen. F cal. Pr>F

$4 \quad 30638,35 \quad 41,45 \quad 299,25 \quad 102,39 \quad 0,0001$

Erro: 0,1190 QMB $(L)+1,0455$ QMT*L - 0,1645 QMRes

Tratam. GLNum. QMNum. GLDen. QMDen. F cal. Pr>F

$14 \quad 641,17 \quad 60,08 \quad 170,54 \quad 3,76 \quad 0,0002$

Erro: 0,3055 QMT*L + 0,6945 QMRes

B1(Local) GLNun. QMNum. GLDen. QMDen. F cal. Pr>F
15
$120,36 \quad 85,99$
72,26
1,67
0,0735

Erro: QMRes

Trat*Loc GLNun. QMNum. GLDen. QMDen. F cal. Pr $>$ F

$\begin{array}{llllll}56 & 155.06 & 30,00 & 35,83 & 4,33 & 0,0001\end{array}$


Tabela 40. Composição da estatistica "F", obtida atravé de opç̃o TEST do comando RANDON para a Soma de Quadrados Tipo II.

CV

Erro: 2,00 QMB(L) + 1,7611 QMT*L - 2,7611 QMRes

Local GLNun. QMNum. GLDen. QMDen. F cal. Pr>F

4. $\quad 30638,35 \quad 32,22 \quad 379,70 \quad 80,69 \quad 0,0001$

Erro: 1,0318 QMT*L - 0,0318 QMRes

Tratam. GLNum. QMNum. GLDen. QMDen. F cal. Pr $>F$

$14 \quad 585,15 \quad 55,20 \quad 158,85 \quad 3,68 \quad 0,0002$

Erro: QMRes

Bl(Local) GLNun. QMNum. GLDen. QMDen. F cal. Pr>F

$\begin{array}{llllll}15 & 102,78 & 30,00 & 35,83 & 2,87 & 0,0068\end{array}$

Erro: QMRes

Trat*Loc GLNun. QMNum. GLDen. QMDen. F cal. Pr>F

$\begin{array}{llllll}56 & 155.06 & 30,00 & 35,83 & 4,33 & 0,0001\end{array}$


Tabela 41. Composiça da estati stica "F", obtida através da opça TEST do comando RANDON para as Somas de Quadrados Tipos II $e$ IV.

CV

Erro: 1,4706 QMB(L) + 0,8288 QMT*L - 1,2994 QMRes

Local GLNun. QMNum. GLDen. QMDen. F cal. Pr $>$ F

$4 \quad 22168,36 \quad 28,74 \quad 233,09 \quad 95,10 \quad 0,0001$

Erro: 0,9267 QMT*L - 0,0233 QMRes

Tratam. GLNum. QMNum. GLDen. QMDen. F cal. Pr $>$ F

$14 \quad 564,64 \quad 56,62 \quad 152,28 \quad 3,74 \quad 0,0002$

Erro: QMRes

Bl(Local) GLNun. QMNum. GLDen. QMDen. F cal. Pr>F

$\begin{array}{llllll}15 & 102,78 & 30,00 & 35,83 & 2,87 & 0,0068\end{array}$

Erro: QMRes

Trat*Loc GLNun. QMNum. GLDen. QMDen. F cal. Pr>F

$\begin{array}{llllll}56 & 155.06 & 30,00 & 35,83 & 4,33 & 0,0001\end{array}$


Assim, devido ao problema de multicolinearidade en contrado nas colunas da matriz de delineamento, os resultados obti dos pela aplicaça da opç̃o TEST parecem ser mais apropriados.

Um estudo desenvolvido por NOGUEIRA (1976), baseado em trabalhos realizados por vários autores, chegou a resultados condizentes com a Soma de Quadrados Tipo I fornecida pelo SAS. No presente trabalho, verificou-se que esta soma de quadrados não parece ser a mais adequada para o delineamento em blocos aumentados, conforme fol verificado atraves das hipóteses testadas para esta soma de quadrados.

As somas de quadrados Tipos II e III não diferiram em termos de hipoteses testadas, mas sim em termos dos coeficientes que antecedem os componentes de variancia, incluidoe nas $E$ [QM] dos efeitos do modelo. Este fato está relacionado a maneira como a matriz de delineamento é particionada para o cálculo dos quatro ti pos de somas de quadrados.

O programa utilizado na execuça dessa análise é apresentado como Apendice. 


\section{CONCLUSOES}

Considerando-se os objetivos e as informações obtidas neste estudo, pode-se concluir o seguinte:

- Na análise individual, a estatística " $F$ " para o efeito de tratamento na Soma de Quadrados Tipo I pode ser obtida através da composição do quadrado médio do denominador.

- A Soma de Quadrados Tipo I não mostrou ser a mais adequada na análise conjunta, pois verificou-se que as hipóte ses testadas para cada efeito do modelo contem, além do efeito de interesse, outros efeitos embutidos.

- Embora as Esperancas dos Quadrados Médios nas Somas de Quadrados Tipos II e III não difiram em termos de componentee de variancia, sabe-se que, de acordo com o Manual do SAS (1987), a Tío II é adequada para modelos balanceados e que não possuam efeitos contidos em outros efeitos. Portanto, é razoável considerar que a Soma de Quadrado Tipo III parece ser a mais indicada, na análise conjunta.

- O resultado apresentado como padrão ("default") na Soma de Quadrados Tipo III, pelo SAS, que calcula a estatística F através do quadrado médio do resíduo, não é adequado. Para a aná 
lise conjunte foi verificado que é necessario fazer uma composiça do quadrado médio do denominador para alguns efeitos do modelo.

- Devido aos problemas de multicolinearidade que podem ocorrer nas colunas da matriz de delineamento, a obtença da estatística F atraves da opcão TEST do comando RANDOM apresenta a eficiéncia desejada. 


\section{REFERENCIAS BIBLIOGRAFICAS}

CARVALHO, L.R. Blocos casualizados com tratamentos comuns: uma aplicação em melhoramento genético de soja, Piracicaba, 1991. SP. (Mestrado - Escola Superior de Agricultura "Luiz de Quei$\operatorname{roz}^{\prime \prime} /$ USP ). $80 \mathrm{p}$.

COCHRAN, W.G. The combination of estimates from different experimente. Biometrics, Alexandria, 10: 101-129. 1954.

FEDERER, W.T.. Augmented ( or Hoonuiaku) designs. Hawailan Planter's Record, Alea, 55: 191-208. 1956.

FEDERER, W.T. Augmented design with one way elimination of heterogeneity. Biometrics, Alexandria, 17: 447-73. 1961.

FEDERER, W.T. Augmented design with two, three and higher way elimination of heterogeneity. Biometrics, Alexandria 17: 16672. 1961 .

FERRARI, F.. Sobre estimadores viesados para modelos de regressão em presença de multicolinearidade, Piracicaba, 1989. SP. (Doutorado - Escola Superior de Agricultura "Luiz de Queiroz"/USP). 121 p.. 
GONÇALVEZ, N.M.. Comparação de diversas metodologias para a análise de um delineamento aumentado com tratamentos fixos e aleátórios. Fundaça Univereidade de Bragilia, Brasilia - DF. 1984. $98 \mathrm{p}$.

GREINER, L.C.. Análise conjunta de experimentos em blocos incompletos balanceados com alguns tratamentos em comum, Piracicaba, 1986. SP. Mestrado - Escola Superior de Agricultura "Luiz de Queiroz/ USP). 89 p.

IEMMA, A.F. \& PALM, R.. Statistical hypothesis and orthogonal projectione for unbalanced data. IN: CONGRESO IBEROAMERICANO, 1. REUNI ON NACI ONAL DE ESTADI STICA E INVESTIGACION OPERATIVA, 20 . Espanha. Resumos. 1992.

IEMMA, A.F. Analisis de varianza de experimentos con celdas vazias. $\varphi$ o p Publicaç̧̃es, Bogota, Colombia, 102 p.. 1993.

LIN, C.S. \& POUSWINSKY, G.. A modified augmented design for an early stage of plant selection involving a large number of test Ines without replication. Biometrics, Alexandria 39: 553-61. 1983

LIN, C.S. \& POUSWINSKY, G.. A modified augmented design (type 2) for rectangular plots. Canadian Journal of Plant Science. Ottawe. $65: 743-49.1985$.

MILLIKEN, G.A. \& JOHNSON, D.E. Analysis of messy data. New York, Van Nostrand Reinhold Company. 473 p. 1984. 
NOGUEIRA; M.C.S.. Análise conjunta para experimentos em blocos casualizados completos aumentados. Pirac1caba, 1976. SP. (Megtrado - Escola Superior de Agricultura "Luiz de Queiroz"/USP). $49 p$.

OLIVEIRA, A.C.. Experimentos em reticulado quadrado com alguns tratamentos comuns adicionados em cada bloco. Analise com recuperaça da informaça interblocos. Pesquisa Agropecuária Brasileira, Brasilia, 25 (3): 289-98. 1990a.

OLIVEIRA, A.C.. Experimentos em blocos incompletos parcialmente balanceados (PBIB) com tratamentos comuns adicionados em cada b1000. Pesquisa Agropecuária Brasileira, Bresi lia, 25 (4): 46990. $1990 \mathrm{~b}$.

OVERALI, J.E. \& SPIEGEL, D.K. Concerning least square analysis of experimental data. Psychological Bulletin, $72: 311-22,1969$.

PEARSON, E.S. \& HARTLEY, H.O. Biometrika tables for statisticians. 1 ediça. Cambridge, The University Press. 238 p. 1956.

PIMENTEL GOMES, F.. An extension of the method of joint analysis of experiments in complete randomised blocks. Biometrics, Ale xandria, 26: $331-36.1970$.

PIMENTEL GOMES, F. Curso de estatistica experimental. $8^{a}$ edicão. Livraria Nobel, Säo Paulo. 1978. 430 p.. 
PIMENTEL GOMES, F. \& GUIMARAES, R.F.. Joint analysis of experiments in complete randomised blocks with some common treatments Biometrics, Alexandria, 14: 521-26. 1958.

SAS Institute Inc. SAS for Linear Models. Cary, NC: SAS Institute Inc., 1981.287 p..

SAS Institute Inc. SAS/STAT Guide for Personal Computers, Version 6 Edition. Cary, NC: SAS Institute Inc., 1987. 1028 p..

SAS Institute Inc. SAS/IML User's Guide, Release 6.03 Edition. Cary, NC:SAS Institute Inc., 1988. $357 \mathrm{p}$.

SATTERTHWAITE, F.E.. Synthesis of variance. Psychometrika. Chicago, $6(5): 309-16.1941$.

SATTERTHWAITE, F.E.. An aproximate distribution of estimates of variance components. Biometrics Bulletin. Washington, 2 : $110-$ 14. 1946.

SEARLE, S.R.. Linear models. New York, John W1ley \& Sone. 532 p. 1971.

SEARLE, S.R. Linear models for umbalanced data. New York, John Wiley \& Sons. 536 p. 1987.

SILVA, E.A.. Análise de covariancia em delineamentos de blocos completos aumentados (Blocos de Federer). P1racicaba, 1987.SP. (Mestrado - Escola Superior de Agricultura "Luiz de Queiroz"/ USP). 87 p. 
SPEED, F.M. \& HOCKING, R.R.. The use of the R ( ) notation with unbelanced data. The American Statistician, Alexandria, 30: $30-$ 3. 1976 .

VIZONI, E.. Análise de experimentos em blocos casualizados completos aumentados (Blocos de Federer), com parcelas subdivididas no tempo. Piracicaba, 1984. SP (Mestrado - Escola Superior de A gricultura "Luiz de Queiroz" / USP). 98 p.

YATES, F. The analysis of multiple classifications with unequal numbers in the different classes. Journal American Statistical Association, $29: 51-66.1934$. 
Apendice: Programa desenvolvido para realizar as analises indivi duais por local e $\mathrm{a}$ análiee conjunta atraves do SAS $(1987)$.

OPTIONS NODATE PS=65;

DATA tese;

INPUT 1 t $b$ prod; OUTPUT;

CARDS;

111107

121100

........

545100

;

* ANALISE POR LOCAL OU EXPERIMENTO * $/$

PROC GLM;

BY 1;

CLASS $t b$;

MODEL prod=t b, E E1 E2 E3 E4 SS1 SS2 SS3 SS4 SOLUTION;

RANDOM b/Q TEST;

RUN;

* ANALISE CONJUNTA*

PROC GLM;

CLASS $1 t b$;

MODEL prod=1 $t$ b(l) $t * 1 / E$ E1 E2 E3 E4 SS1 SS2 SS3 SS4 SOLUTION;

RANDOM $1 \mathrm{~b}(1) \mathrm{t} * 1 / \mathrm{Q}$ TEST;

RUN; 